Sharifzadeh M, Rashtchian D, Pishvaie MR, Thornhill NF, (2011). Energy induced separation network synthesis of an olefin compression section: a case study. Industrial \& Engineering Chemistry Research, 50 (3), 1610-1623, (Link).

\title{
Energy Induced Separation Network Synthesis of an Olefin Compression Section: a Case Study
}

\author{
M. Sharifzadeh ${ }^{* 1,2}$, D. Rashtchian ${ }^{1}$, M. R. Pishvaie ${ }^{1}$, N. F. Thornhill ${ }^{2}$ \\ ${ }^{1}$ Department of Chemical and Petroleum Engineering, Sharif University of Technology \\ ${ }^{2}$ Centre for Process System Engineering (CPSE), Department of Chemical Engineering and \\ Chemical Technology, Imperial College London.
}

\begin{abstract}
When latent heat is transferred in a heat exchanger network, the formation of the second phase creates an opportunity for separation. This network is known as a Heat Induced Separation Network (HISEN). HISENs have been extended to include pressure adjusting devices for improving the thermodynamic feasibility of the network. This extended network is termed an Energy Induced Separation Network (EISEN). Most examples of EISENs in the literature are environmental pollution treatment case studies which do not require liquid phase mass integration or shaft power integration. They assume a predetermined extent of separation, and mostly are based on conceptual methods of design. This paper explains how the optimization framework must be developed in order to systematically address the general characteristics of EISENs. The framework is illustrated using a case study of the synthesis problem of an olefin compression section.
\end{abstract}

Keywords: EISENs, HISENs, Process Synthesis, Superstructure, olefin compression section, process integration.

\footnotetext{
*Mahdi Sharifzadeh (mahdi@imperial.ac.uk)., Centre for Process Systems Engineering, Department of Chemical Engineering, Imperial College London, South Kensington Campus, London SW7 2AZ
} 


\section{Please cite the following article at:}

Sharifzadeh M, Rashtchian D, Pishvaie MR, Thornhill NF, (2011). Energy induced separation network synthesis of an olefin compression section: a case study. Industrial \& Engineering Chemistry Research, 50 (3), 1610-1623, (Link).

\section{Introduction and background}

In the last three decades, rising energy prices, stringent environmental regulations and close competition of technology suppliers have motivated academic and industrial researchers to study systematic methodologies for process optimization, generally in the three areas of synthesis, design and operation ${ }^{1}$. Particularly, in the case of processes with very high energy consumption, the systematic approaches may result in significant economic benefits, notably the Energy Induced Separation Network (EISEN) synthesis scheme which refers to a network of heat exchangers and also pressure-adjusting devices that realizes a separation target via latent heat exchange. In this paper, this methodology is reviewed through introducing a synthesis problem of an olefin compression section, which is a motivating example of an EISEN synthesis with simultaneous heat, mass, and power exchange and provides opportunity of integration between these tasks.

The origins of EISEN synthesis are in Pinch Analysis and mass integration. Following the introduction of Pinch Analysis by Linnhoff ${ }^{2,3}$, its usefulness and clarity were employed for mass integration by El-Halwagi ${ }^{4,5}$. He replaced the requirement of the minimum approach temperature by the minimum approach composition in order to guarantee the existence of the vital driving force for mass transfer as the thermodynamic constraint. Thereafter, many concepts such as mass exchanger, separating agents, separation extent and many graphical tools such as mass pinch diagram, path diagrams, and sink/source (mass) mapping diagrams ${ }^{6-9}$ were innovated and employed for mass integration.

The mass integration techniques can be classified into two general categories, depending on whether they employ mass separating agents such as adsorbents, solvents, ion-exchange resins or 


\section{Please cite the following article at:}

Sharifzadeh M, Rashtchian D, Pishvaie MR, Thornhill NF, (2011). Energy induced separation network synthesis of an olefin compression section: a case study. Industrial \& Engineering Chemistry Research, 50 (3), 1610-1623, (Link).

whether they invoke energy separating agents such as coolants, refrigerants and different steam levels. From numerous separation systems, the instance of Heat Induced Separation Network $(\mathrm{HISEN})^{10}$ is a network of heat exchangers where latent heat transfer via the phase change is employed to achieve separation. Since the equilibrium condition depends on both temperature and pressure, HISEN has been extended to include pressure adjusting devices such as compressors, turbines and throttling valves, with the generalized title of EISEN ${ }^{11}$. The driving force for heat transfer is the temperature difference. This driving force, in turn, constrains the synthesis of heat exchange networks. However, by pressurizing and depressurizing of a gaseous stream, its temperature will be modified to provide the opportunity of heat transfer between streams which did not have the required driving force. The EISEN employs these extra degrees of freedom to enhance the separation via transfer of latent heat.

The EISEN and HISEN, both, were originally developed for separation of pollutants from gaseous emissions to the environment, known as end-of-pipe treatment. These two techniques have also proved their usefulness for in-plant waste minimization and source reduction ${ }^{12,13}$. By contrast with the end-of-pipe treatment, in the in-plant source reduction methodology emissions are reduced by optimizing the operational variables before the undesired species are produced and propagated in the plant. In addition to the separation task, condensate allocation (and potential mixing of the recovered condensates with fresh make-up) must be considered in order to decrease the requirements for importing mass separating agents ${ }^{14}$. Later, clustering analysis was employed by El-Halwagi for multi-component mixtures in order to overcome the limitations of pinch-oriented graphical tools ${ }^{15}$. Recently simulator software tools have been deployed to capture non-ideality of the mixture equilibrium in order to construct the temperature path of the 


\section{Please cite the following article at:}

Sharifzadeh M, Rashtchian D, Pishvaie MR, Thornhill NF, (2011). Energy induced separation network synthesis of an olefin compression section: a case study. Industrial \& Engineering Chemistry Research, 50 (3), 1610-1623, (Link).

condensing fluid ${ }^{16}$. The above examples show that EISEN synthesis has been addressed mostly by conceptual methods. Although these methods exploit physical laws such as second law of thermodynamics to manage problem complexity, they are limited to ad hoc applications by their solo-dimensionality. An example of solo-dimensionality is that, in order to meet a desired separation extent requirement, a target separation temperature should be calculated by employing the equation of state so that achieving that level of chilling would guarantee the desired separation (i.e., condensation) extent ${ }^{10}$. In other words, the mass transfer task must be translated to heat transfer duty with predetermined condensation path that in turn requires a predetermined profile for composition. However, it is not possible to apply this approach also for the power integration, (i.e., translating compression task to heat transfer duty) because processes involved in power integration are concerned with energy conversion from one type to another type (e.g., internal energy to kinetic energy or the reverse), and have different natures.

By contrast, there are also process synthesis and integration approaches which are based on mathematical modeling and optimization of the process superstructure. The case study of olefin compression section, presented in this paper, is addressed using this approach. The key feature of this methodology is to develop and employ a superstructure model of the process that provides the opportunity for the optimization algorithm to decide on the configuration and design specification of the process, often through an economic objective function. In this framework, the mathematical model of the process, embedded within a superstructure, represents physical constraints of the optimization programming, and ensures the consistency of model and physical process in sufficiently wide range of the design space. In addition, construction of a superstructure facilitates consideration of alternative design configurations. These methodologies 


\section{Please cite the following article at:}

Sharifzadeh M, Rashtchian D, Pishvaie MR, Thornhill NF, (2011). Energy induced separation network synthesis of an olefin compression section: a case study. Industrial \& Engineering Chemistry Research, 50 (3), 1610-1623, (Link).

are more likely to encompass the global solution through exploring the feasible space and they provide the opportunity for simultaneous addressing the conflicting design objectives as discussed by Zhelev ${ }^{17}$. However, attempting the formulation of the EISENs in a mathematical framework does face some difficulties including the construction of a feasible superstructure and the need for constrained mixed-integer optimization programming. The main contribution of the work presented in this article is mathematical modeling and optimization programming for EISEN synthesis. This approach will consider all the conflicting tasks of mass, heat and power exchange simultaneously through an economic objective function that guarantees the optimality of the design solution. In addition, this is the first time that EISEN synthesis is formulated for an application which is not an in-plant or end-of-pipe waste treatment, but as an economic bottleneck of a mature process such as olefin production plant.

The paper is laid out as follows. This section has presented a survey of previous work on EISENs. Section 2. presents the problem statement and the general characteristic of the EISENs and discusses the general optimization framework for the synthesis problem of the EISENs. Section 3. gives an overall description of a typical olefin process, required for the case study development. This section also explains how the case of olefin compression section aligns with the general characteristics of EISENs, described in Section 2.2. Then, in Section 4. the presented optimization framework is applied to the case of the olefin compression section. Section 5. discusses the solution of the simulation-optimization synthesis problem. Finally, an overview of each design factor and its economic significance will be presented.

\section{The general optimization framework for the energy induced separation network}

This section presents a general optimization framework for the energy induced separation 
Please cite the following article at:

Sharifzadeh M, Rashtchian D, Pishvaie MR, Thornhill NF, (2011). Energy induced separation network synthesis of an olefin compression section: a case study. Industrial \& Engineering Chemistry Research, 50 (3), 1610-1623, (Link).

networks (EISENs). Firstly, the problem statement is presented. In addition, the general characteristics of the energy induced separation networks is reviewed. Then, it is possible to present a general optimization framework for the EISENs. Later, as the optimization framework is being developed for the olefin compression section, the characteristic of the EISENs and the general optimization framework will be referred in the corresponding sections.

\subsection{The problem statement}

The statement of the problem for the EISEN synthesis is shown in Figure 1. adopted from ${ }^{11,16}$ and is described in the following.

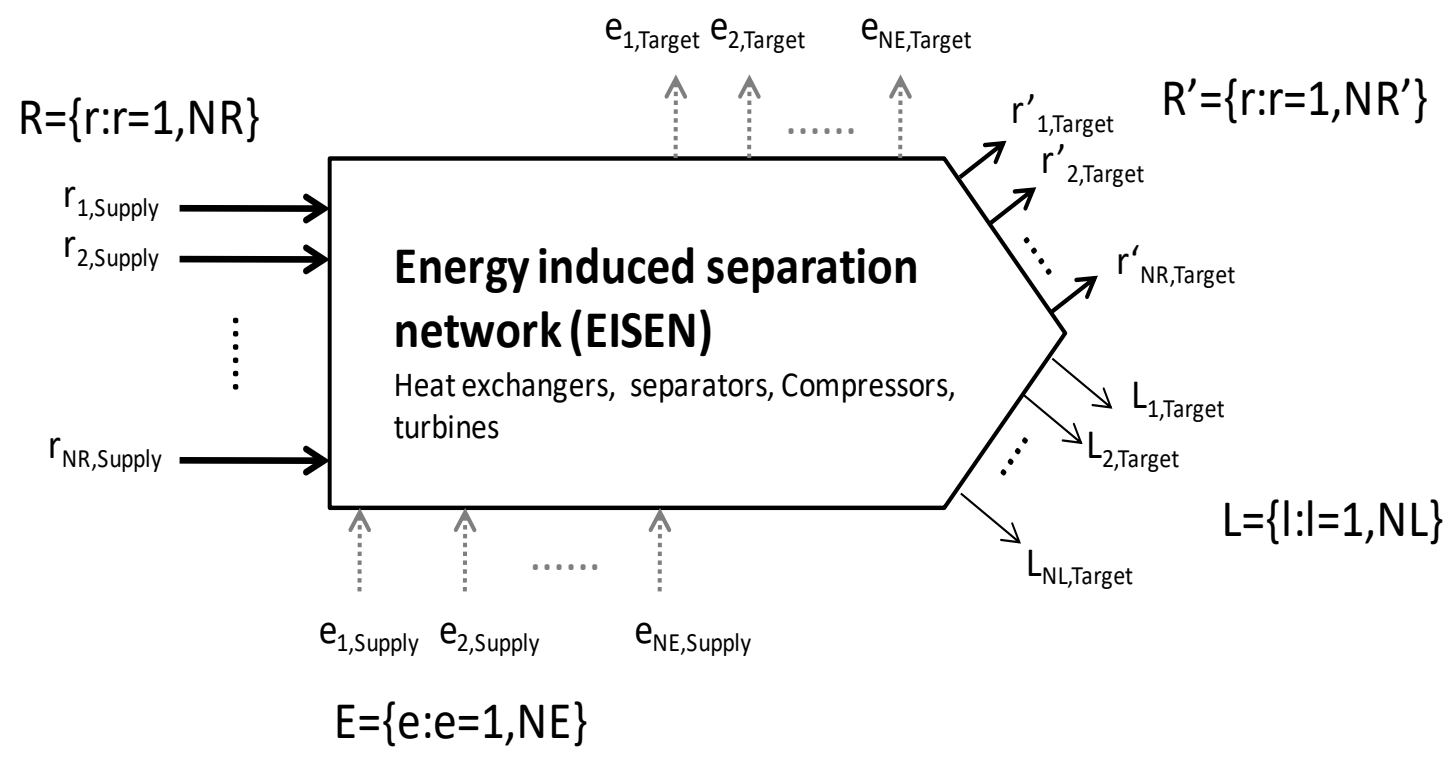

Figure 1. Problem statement of synthesizing energy induced separation network adopted fom ${ }^{11}$.

Given a set of, $R=\{r: r=1, N R\}$, rich (waste) gaseous streams, a set of, $E=\{e: e=1, N E\}$, energy separating agents (ESA), synthesize a network of indirect-contact heat induced separators along with pressurization/depressurization devices, which can recover a certain fraction of condensable species at a minimum cost. 


\section{Please cite the following article at:}

Sharifzadeh M, Rashtchian D, Pishvaie MR, Thornhill NF, (2011). Energy induced separation network synthesis of an olefin compression section: a case study. Industrial \& Engineering Chemistry Research, 50 (3), 1610-1623, (Link).

In this problem statement, rich or waste streams are those streams containing species which are separable via phase change. An indirect-contact heat induced separator is a heat exchanger followed by a separator or a partial heat exchanger that provides opportunity for exchange of latent heat via phase change and then separation of gas and liquid phases. Energy separating agents are energy carriers such as cooling water or refrigerants, which in indirect contact with rich streams promote the separation via the phase change. Hot energy carriers such as steam at different levels also fall into this category. These energy carriers are employed by pressurizing/depressurizing devices such as turbines or compressors, which promote the separation through adjusting the pressure of rich streams.

\subsection{The problem characteristics}

The review by Dun and El-Halwagi ${ }^{6}$ has summarized the general characteristics of the EISEN synthesis problem. These authors posed a series of questions (their words):“(a) Which energy separating agents should be employed?(b) Should stream pressurization or depressurization be employed and, if so, to what level?(c) What is the optimal mass and heat load to be removed/added by each ESA?(d) How should the waste and ESA streams be matched (i.e., stream pairings)?(e) What is the optimal system configuration (e.g ., how should the heatinduced separators, heat exchangers and compressors/turbines be arranged?, is there any stream splitting and mixing?)?”. The work reported in this paper addresses these questions in a systematic way.

\subsection{The general EISEN optimization framework}

Developing an optimization framework for EISEN consists of three steps: (i) defining an objective function, (ii) identifying the optimization constraints including the development of a 


\section{Please cite the following article at:}

Sharifzadeh M, Rashtchian D, Pishvaie MR, Thornhill NF, (2011). Energy induced separation network synthesis of an olefin compression section: a case study. Industrial \& Engineering Chemistry Research, 50 (3), 1610-1623, (Link).

superstructure for the separation network, and (iii) identifying the optimization variables. It is notable that the selection of the optimization variables follows the step of identifying constraints and superstructure construction. The reason is that the number of optimization variables is the subject of degrees of freedom analysis. The activities of construction of a superstructure and defining the constraints might introduce new equations and optimization variables which would change the degrees of freedom.

The objective function measures the economic performance of the synthesized network, which is defined in terms of the capital investment, the operating costs, and the products revenue.

The superstructure is represented as a set of equality constraints in the optimization framework. Then, by optimizing the values of the synthesis variables this superstructure is pruned into a process model with the optimal configuration. The other constraints typically concern the technical and the safety limitations of the process equipment or the requirements of the separation network such as the minimum separation extent of the condensable materials or the required condition of separated phases leaving the separation network.

The optimization variables consist of a set of synthesis variables and a set of operational variables. The synthesis variables decide on the configuration of the separation network, i.e., selection of the applicable separation technique, decision on the number of the separation stages, selection of the separating agents, decision on the topology of the process. The operational optimization variables decide on the optimal operating conditions of the synthesized process such as operating conditions of the unit operations and the extend of mass and heat exchange between different streams. 
Please cite the following article at:

Sharifzadeh M, Rashtchian D, Pishvaie MR, Thornhill NF, (2011). Energy induced separation network synthesis of an olefin compression section: a case study. Industrial \& Engineering Chemistry Research, 50 (3), 1610-1623, (Link).

The solution of the optimization framework will address the questions posed in Section 2.2. and will indentify the values for the unknown variables in Figure 1.

\section{Case study development: Olefin compression section}

A detailed olefin process description is reviewed in the literature (e.g., Othmers ${ }^{18}$ ). The relevant section for EISEN synthesis is the compression section of olefin plant. The position of this section in relation to other olefin plant sections including hot, cold and pyrolysis gasoline hydrogenation sections is depicted in Figure 2. In addition, Figure 3. shows the olefin compression section of an industrial plant that will be discussed in the following sections.

The olefin process comprises a hot section where the pyrolysis reactions take place in furnaces to produce cracked gas. After cooling, the cracked gas enters the compression section, described in Section 3.2, which is the focus of this paper. The main purpose of the compression is enhancing gas pressure for the downstream cold section in which the volatile products are separated. This separation requires refrigeration and is energy intensive. However, on the other side of the compression section, the condensing nonvolatile products leave the compression section and go to the pyrolysis gasoline hydrogenation section. Hence, the idea of using the compressor section as an EISEN is the compression of cracked gas for downstream distillation requirements and at the same time pre-separation of condensable pyrolysis gasoline for energy saving. These are two competing tasks. 
Please cite the following article at:

Sharifzadeh M, Rashtchian D, Pishvaie MR, Thornhill NF, (2011). Energy induced separation network synthesis of an olefin compression section: a case study. Industrial \& Engineering Chemistry Research, 50 (3), 1610-1623, (Link).

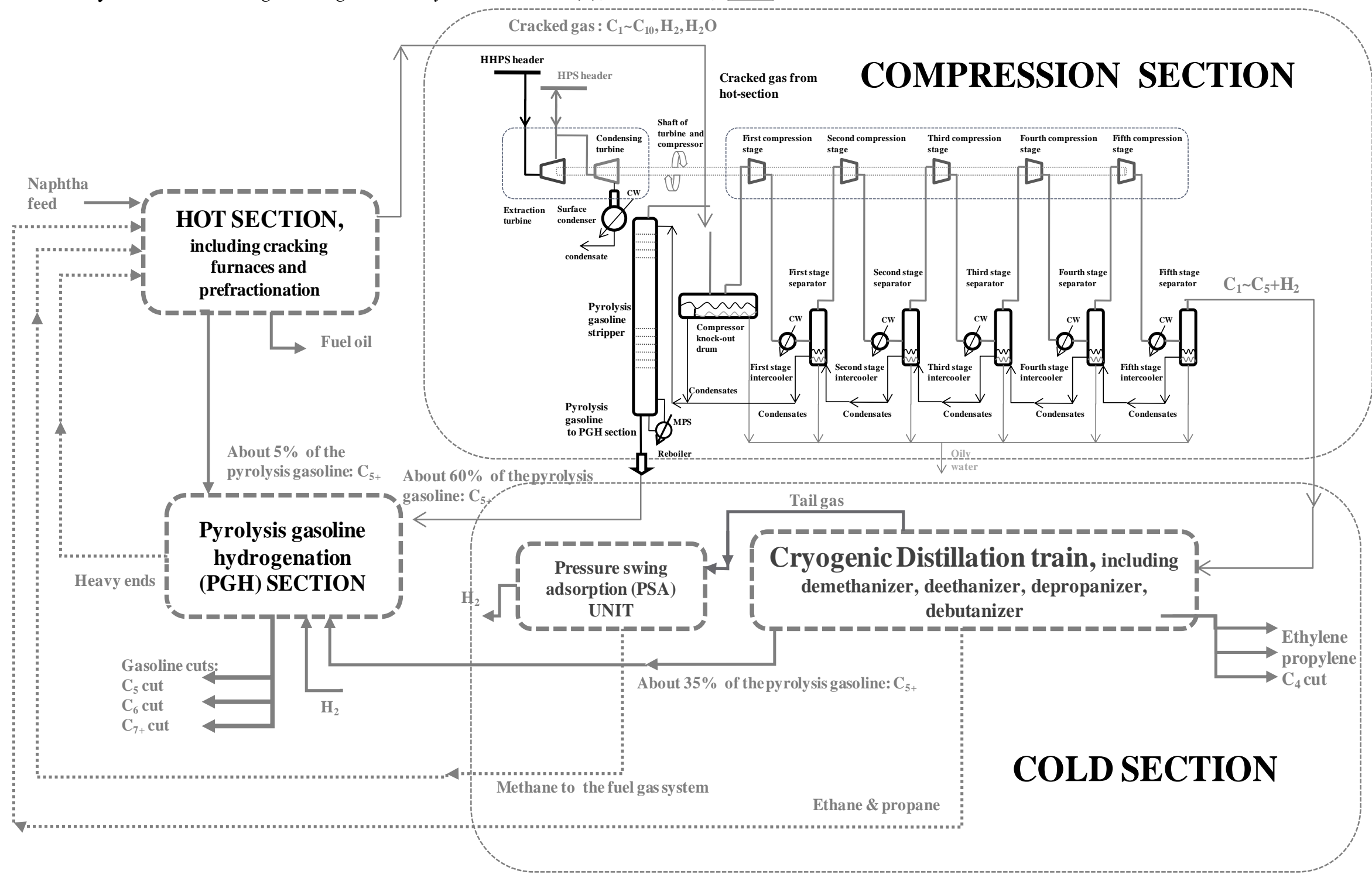

Figure 2. Olefin plant block diagram including hot, compression, cold and pyrolysis gasoline hydrogenation sections. 
Please cite the following article at:

Sharifzadeh M, Rashtchian D, Pishvaie MR, Thornhill NF, (2011). Energy induced separation network synthesis of an olefin compression section: a case study. Industrial \& Engineering Chemistry Research, 50 (3), 1610-1623, (Link).

\subsection{Compression section}

In the compression section (Figure 3), cracked gas is pressurized up to the requirements of the downstream cryogenic distillation train by a multistage compressor train. Considering the polymerization risk of highly reactive diolefins, compression ratios (and implicitly, cracked gas exit temperature in each stage) must be strictly bounded to avoid fouling and deposit formation within the compressors and on the discharge side of each stage. Therefore, hot exiting gas is cooled in each intercooler by cooling water and then fed to the next stage. The successive compressing and cooling of cracked gas will result in formation of condensates (up to $20 \%$ of the cracked gas), called pyrolysis gasoline. Here, transfer of the latent heat of hot gases in the intercoolers (see Figure 3) will result in the phase change and separation of the nonvolatile components from the light gases. These condensate streams have $\mathrm{C}_{2}$ and $\mathrm{C}_{3}$ gases dissolved. Therefore, the condensates will be sent to previous separators with lower pressure, where the light gases will be flashed. The final treatment of light gases will be performed in a stripper before leaving the compression section to the downstream pyrolysis gasoline hydrogenation section. In the olefin compression section, both pressure enhancement and latent heat exchange will contribute to separation of the condensable gases. Therefore, this section of the olefin plant is obtained and nominated as a case study for EISEN synthesis. The characteristics of this subprocess are detailed in the next section. 
Please cite the following article at:

Sharifzadeh M, Rashtchian D, Pishvaie MR, Thornhill NF, (2011). Energy induced separation network synthesis of an olefin compression section: a case study. Industrial \& Engineering Chemistry Research, 50 (3), 1610-1623, (Link).

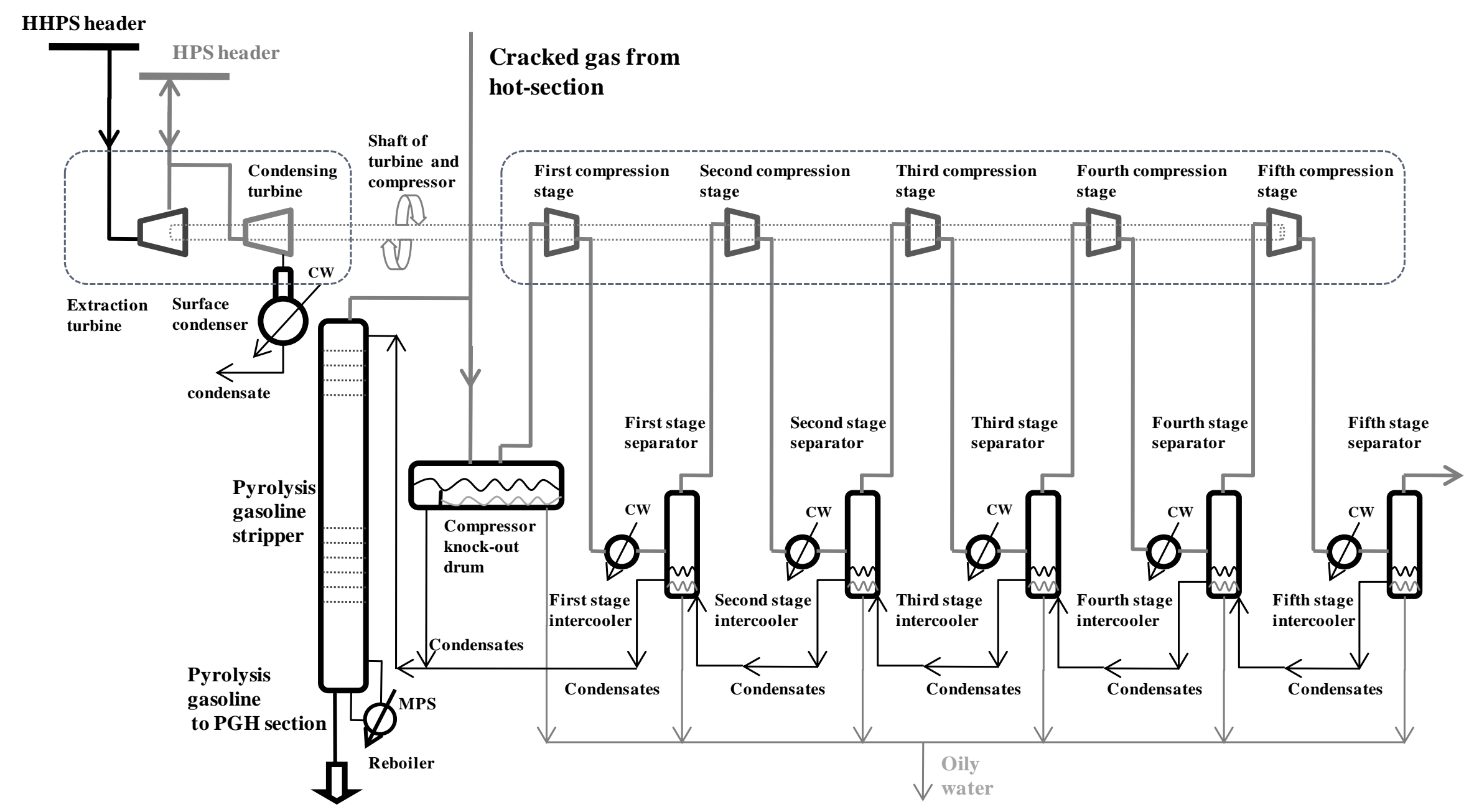

Figure 3. Overall PFD of Compressor Sections. 
Please cite the following article at:

Sharifzadeh M, Rashtchian D, Pishvaie MR, Thornhill NF, (2011). Energy induced separation network synthesis of an olefin compression section: a case study. Industrial \& Engineering Chemistry Research, 50 (3), 1610-1623, (Link).

\subsection{Olefin compression section as an EISEN case study}

A comparison between olefin compression section and the original problem statement of EISEN is illustrative. Following this comparison, the justifications behind selection of olefin compression section as a case of EISEN are discussed

\subsubsection{Alignment between olefin compression and EISEN problem statement}

Table 1. shows how the case of the olefin compression maps onto the aspects of the problem identified in Section 2.1. and Figure 1.

\begin{tabular}{|l|l|}
\hline Aspects of EISEN problem & Olefin compression section \\
\hline Rich (waste) streams & $\begin{array}{l}\text { The entering cracked gas containing considerable amount of } \\
\text { condensable hydrocarbons (i.e. pyrolysis gasoline) and water. }\end{array}$ \\
\hline Indirect-contact heat induced separators & Inter-stage coolers, surface condenser, reboiler \\
\hline Energy separating agent & Cooling water, MPS used in reboiler \\
\hline Hot energy carriers & HHPS, and HPS used in the turbine \\
\hline Pressurizing/depressurizing devices & Multi-stage compressor coupled with two-stage turbine \\
\hline
\end{tabular}

Table 1. One-to-one correspondence between olefin compression section and general characteristics of EISENs.

The synthesis task includes optimization of process configuration and determination of optimal usages of steam and cooling water in order to separate the pyrolysis gasoline and water from cracked gas. The constraints include minimum approach temperature at intercoolers, maximum allowable temperature, and desired pressure of cracked gas leaving the compression section.

The olefin compression section features several interesting properties as a case study of energy induced separation network:

- An olefin compression section has the task of separating the pyrolysis gasoline, and must meet the requirements of pressure enhancement up to the desired value for 


\section{Please cite the following article at:}

Sharifzadeh M, Rashtchian D, Pishvaie MR, Thornhill NF, (2011). Energy induced separation network synthesis of an olefin compression section: a case study. Industrial \& Engineering Chemistry Research, 50 (3), 1610-1623, (Link).

operation of downstream cryogenic distillation train. These simultaneous tasks must be addressed through a cooperative scheme including mass, heat and power exchange.

- Compared to previously studied cases of EISEN, compression section of olefin plant involves the separation of wide range of component, which requires further treatment of separated condensate by flowing to other stages with lower pressure or striping in a distillation column.

- All the previously cases of EISEN studied in the literature ${ }^{10,11,13,14,16}$ concern the separation of a pollutant before emitting to the environment. Selection of the case of olefin compression section to be studied as an instance of EISEN aims in broadening the perspective of application of these methodologies into industrial process design and synthesis rather than end-of-pipe and in-plant waste treatment.

- The case of olefin compression section includes also decisions regarding generation and distribution of the required power. This characteristic was not explored in the previous case studies.

- Optimization of compressor trains is a major industrial issue, especially where it involves phase change and separation of condensates. Instance of similar processes are LNG and gas processing plants ${ }^{19,20}$, and refrigeration cycles ${ }^{21,22}$. These are processes where latent heat exchange is not economic or even feasible exclusively through heat transfer, and pressure enhancement must be integrated into heat transfer for optimal operation.

- Olefin compression section is selected as an example of applicability of mathematical synthesis to large industrial problems. The superstructure of its flowsheet (Figure 4.) includes 24 unit operation, 69 streams, and rigorous thermodynamic analysis of the 
Please cite the following article at:

Sharifzadeh M, Rashtchian D, Pishvaie MR, Thornhill NF, (2011). Energy induced separation network synthesis of an olefin compression section: a case study. Industrial \& Engineering Chemistry Research, 50 (3), 1610-1623, (Link).

hydrocarbon mixtures including 35 components, that require a high computational burden. Presenting rigorous mathematical modeling and optimization based synthesis of an EISEN synthesis problem at this scale would encourage the application of the presented methodology to other industrial cases.

Based on the abovementioned observations and reasoning, the case of olefin compression section is nominated as the energy induced network to be studied in this research. 
Please cite the following article at:

Sharifzadeh M, Rashtchian D, Pishvaie MR, Thornhill NF, (2011). Energy induced separation network synthesis of an olefin compression section: a case study. Industrial \& Engineering Chemistry Research, 50 (3), 1610-1623, (Link).

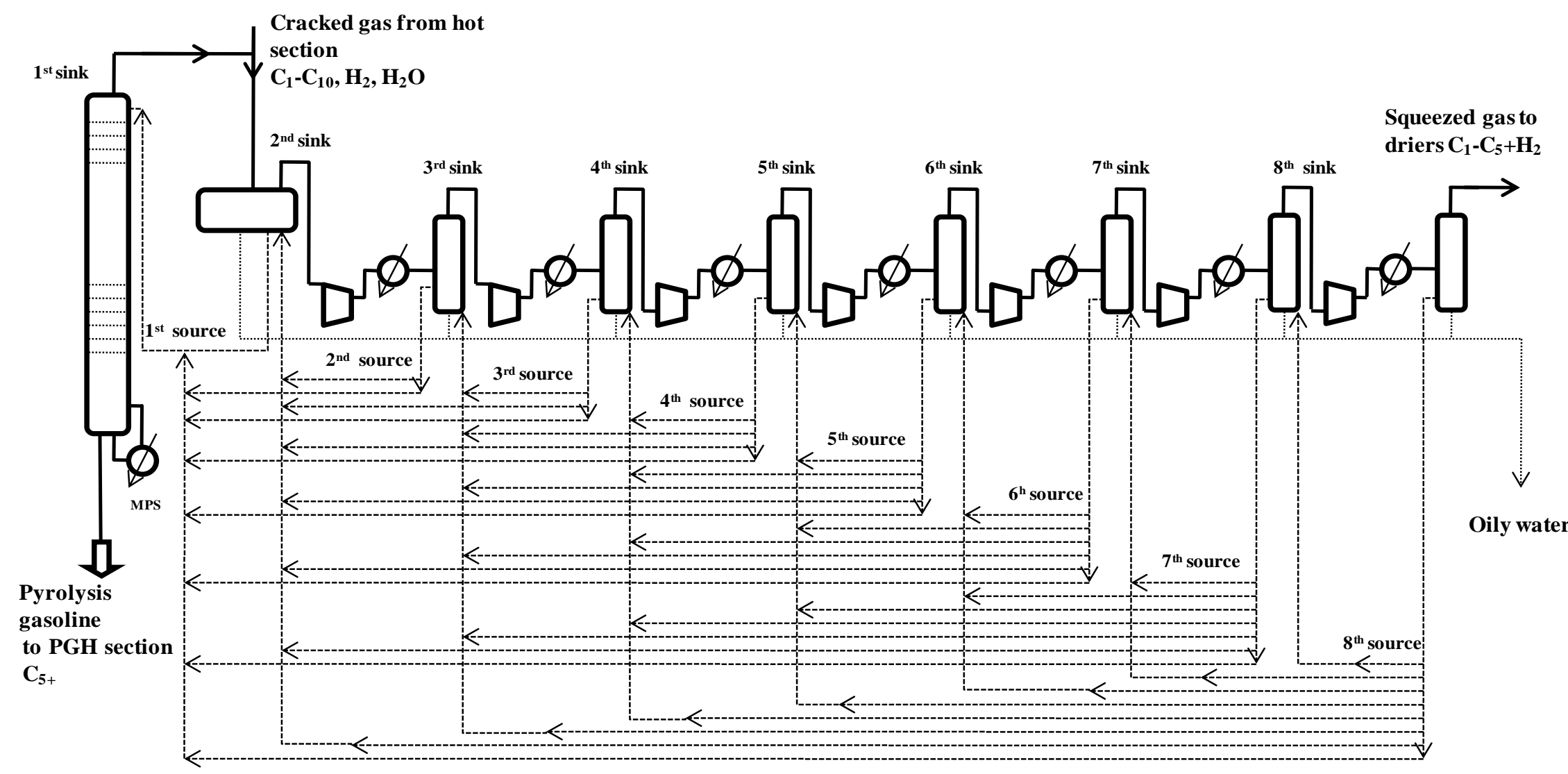

Figure 4. Superstructure representation of the olefin compression section synthesis problem for $\mathrm{N}=7$ (reference to table 9). 
Please cite the following article at:

Sharifzadeh M, Rashtchian D, Pishvaie MR, Thornhill NF, (2011). Energy induced separation network synthesis of an olefin compression section: a case study. Industrial \& Engineering Chemistry Research, 50 (3), 1610-1623, (Link).

\subsection{The olefin compression section: an integrative instance of EISEN}

The multi-dimensional nature of the EISEN invokes the consideration of simultaneous interaction between different involved tasks.

\subsubsection{Power integration}

Power integration involves both sides of the turbine-compressor shaft. On the compression side, the pressure ratio of each compression section defines the amount of power consumption in each stage while at the same time affects the flowrate and composition of the condensates and also increase in the temperature of cracked gas, which relate to mass and heat transfer respectively. On the expansion side of the shaft, however, it is crucial to maximize power generation by optimizing the distribution of high high pressure steam (HHPS) steam, generated in the hot section furnaces, between the backpressure and the condensing stages. Figure 5. shows two stages of the turbine and a surface condenser. The pressure ratio of the first stage of turbine, called the back pressure stage, is from HHPS level to high pressure steam (HPS) level. Here, the internal energy is being converted to mechanical energy as the pressure changes. However, in the condensing stage this transformation of energy will be accompanied by phase change of the steam at the expense of consumption of a cooling medium, i.e., cooling water. The energy released by each kilogram of steam is a function of the pressure ratio of that stage. Hence, by condensation of steam in the surface condenser a degree of vacuum will be achieved that will enhance the power production in the condensing stage. If any HHPS remains unconsumed, it will enter the desuperheater to produce HPS that, in turn, feeds the condensing stage. 
Please cite the following article at:

Sharifzadeh M, Rashtchian D, Pishvaie MR, Thornhill NF, (2011). Energy induced separation network synthesis of an olefin compression section: a case study. Industrial \& Engineering Chemistry Research, 50 (3), 1610-1623, (Link).

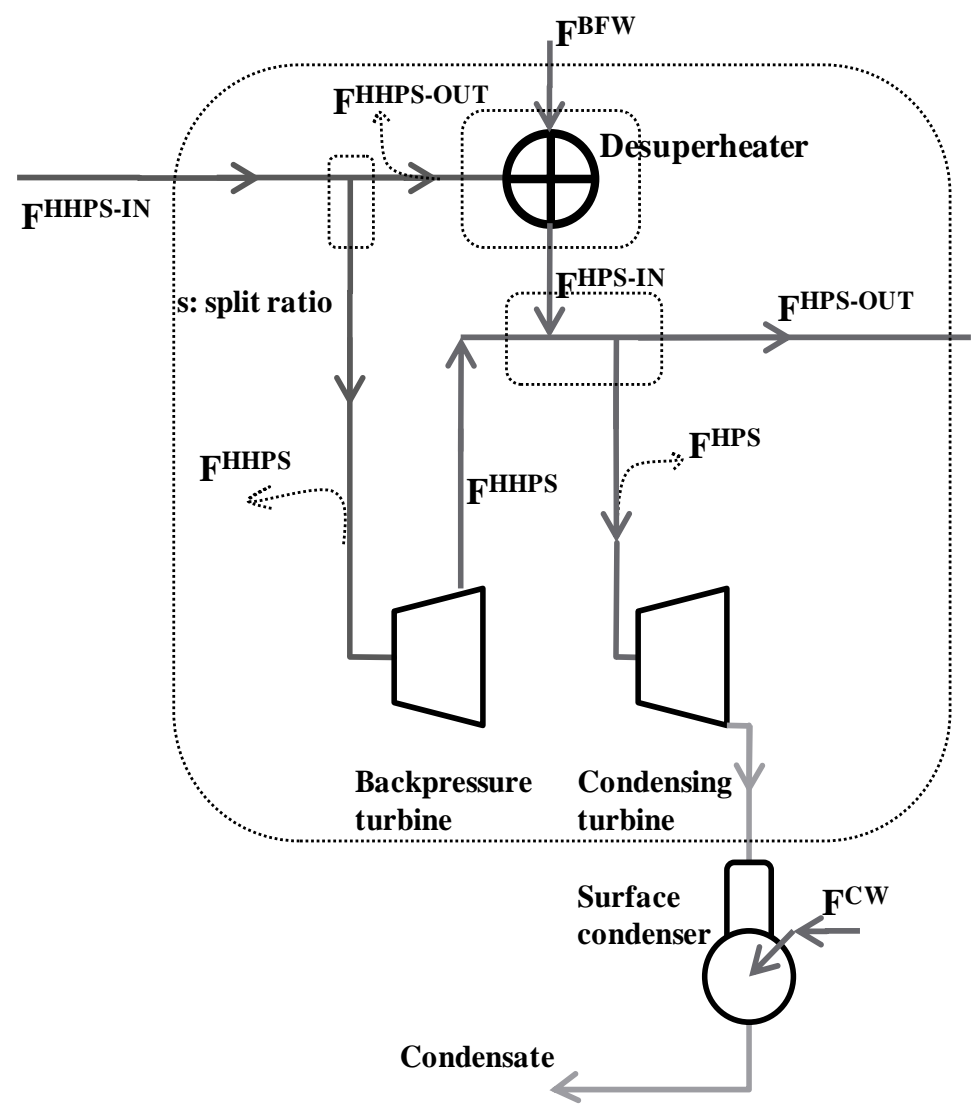

Figure 5. The model of two-stage turbine for optimization of HHPS consumption. $\mathrm{F}^{\mathrm{HHPS}-\mathrm{IN}}$ is generated steam in hot section furnaces and $\mathrm{F}^{\mathrm{HPS}-\mathrm{OUT}}$ is the excess steam to be exported to the site HPS header.

\subsubsection{Mass Integration}

From the mass integration point of view, decisions regarding the condensate flow path affect the amount of cracked gas entering each compression stage and also affect the gas temperature by flashing the dissolved light gases. The persisting dissolved gases in the condensates are stripped in the distillation column and will be recycled to the network. 
Please cite the following article at:

Sharifzadeh M, Rashtchian D, Pishvaie MR, Thornhill NF, (2011). Energy induced separation network synthesis of an olefin compression section: a case study. Industrial \& Engineering Chemistry Research, 50 (3), 1610-1623, (Link).

\subsubsection{Cooling Task and its interaction with mass and power tasks}

The cracked gas entering the compression section contains condensable vapors including hydrocarbons and water, which must be separated before routing to the cryogenic distillation column. The aim of this pre-separation is the reduction of refrigeration costs in the downstream section and elimination of the risk of frost formation. In addition, risk of polymerization limits the temperature of exiting gas from each compression stage, and the cracked gas must be cooled before entering the next stage for further pressurization. This separation target is accomplished through a sequence of compressing and cooling of cracked gas. Therefore, the integrated task of condensate separation and pressure enhancement must follow an optimum path on the temperature-pressure diagram such as the curve that is shown in Figure 6. The difficulty in the design task of the olefin compression section is that the composition of this condensing path is also unknown.

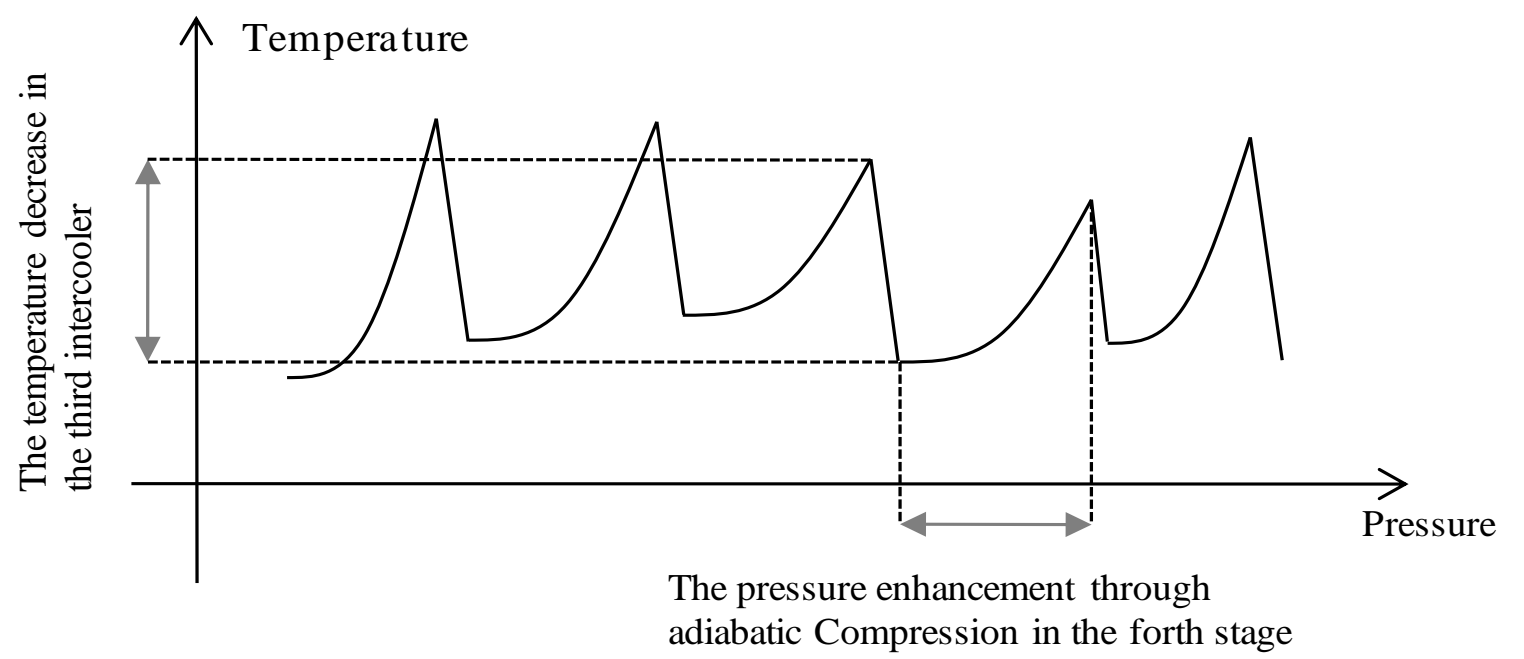

Figure 6. Temperature-pressure diagram for a five-stage compression section

Cooling duty interacts with both the mass and power integration tasks. Cooling directly affects the condensation rates and the composition of condensate which is formed in each stage. As the 


\section{Please cite the following article at:}

Sharifzadeh M, Rashtchian D, Pishvaie MR, Thornhill NF, (2011). Energy induced separation network synthesis of an olefin compression section: a case study. Industrial \& Engineering Chemistry Research, 50 (3), 1610-1623, (Link).

entering gas temperature reduces, it becomes denser and the efficiency of compression process increases. In addition, by separating more condensates, less of the cracked gas undergoes the compression process and power consumption decreases. On the other hand, while the maximum exit temperature is limited by the risk of polymerization, decreasing the temperature of entering gas expands the feasible design space of pressure ratios, leading to conclusion that heat transfer contribution in the olefin compression section is enhancement of mass and power integration.

\subsubsection{Nonsharp extent of separation}

A predetermined extent of separation is not necessarily the optimum nonsharp extent of separation. The separation task in the olefin compression section is nonsharp because pyrolysis gasoline will inevitably penetrate to the cold section downstream and will be separated in the bottom of the tail end debutanizer (the last column), but at the expense of increased separation costs in the cryogenic distillation train. However, this escaped amount of pyrolysis gas must be optimized for a trade-off between product loss and separation costs. Product loss refers to the fact that some of volatile olefin products may also escape to the pyrolysis gasoline hydrogenation plant, which then are not recoverable. Considering the fact that the condensation occurs gradually in sequential stages with different compositions, there are some opportunities for liquid mass integration in order to facilitate this separation, i.e., flowing in countercurrent with gas or recycling directly to the distillation (see Figure 4).

\subsubsection{Targets for optimization}

The interactions described in the preceding sections cannot be captured through the solodimension graphical tools such as pinch diagrams. Olefin compression section is a motivating 
Please cite the following article at:

Sharifzadeh M, Rashtchian D, Pishvaie MR, Thornhill NF, (2011). Energy induced separation network synthesis of an olefin compression section: a case study. Industrial \& Engineering Chemistry Research, 50 (3), 1610-1623, (Link).

example of simultaneous mass, heat and power exchanges that must be addressed by optimization of a mathematical model. Again the benefit of the mathematical approach is its rigor, while in the presence of recycling the conceptual methods (although they are supposed to be systematically programmable) can be erroneous due to their simplifying assumptions (for example, the assumption of predetermined composition for streams). The targets for the simulation-optimization framework of this article are:

1. Providing the possibility of rigorous calculation of thermodynamic properties of the streams,

2. Considering the multi-dimensional nature of EISEN, providing the opportunity of simultaneous mass, heat and power exchange,

3. Optimizing the trade-off between compression and separation tasks of the olefin compression section as the economic bottleneck of the olefin plant, and

4. Providing a conceivable picture of the trade-off between fixed and operating costs of the compression section.

\section{The optimization framework for the olefin compression section}

This section presents the optimization framework for the case of olefin compression section. This framework is aligned with the general framework of EISENs presented in section 2.3.

\subsection{The objective function}

The total annualized costs (TACs) are selected as the objective function for synthesizing olefin 
Please cite the following article at:

Sharifzadeh M, Rashtchian D, Pishvaie MR, Thornhill NF, (2011). Energy induced separation network synthesis of an olefin compression section: a case study. Industrial \& Engineering Chemistry Research, 50 (3), 1610-1623, (Link).

compression section ${ }^{1}$ :

$$
\text { Fitness value }=T A C s+\sum \text { penalty terms }
$$

TACs include capital costs of procurement and installation of process equipment and costs associated with operation of olefin compression section. Additional terms are added to the objective function in order to take account of the violation of constraints. The violation of constraints will be driven to zero by the convergence of the optimizer. These terms include the violation of the target pressure of the leaving cracked gas, violation of the constraints on the exiting temperatures at each compression stages and the constraints on the structural variables for condensate flow. These constraints are discussed in the following sections.

\subsection{Identifying the constraints}

The constraints on the synthesis optimization problem consists of the equality constraints associated with process model embedded in a superstructure and the other equality or inequality constraints which concern about the technical limitations or the process requirements.

\subsubsection{Construction of the superstructure}

Superstructure construction has been reviewed by many authors (e.g., Heckl ${ }^{27}$ ). It is important to note that once the synthesis task is formulated, any engineering preference, judgment, and insight are set aside. Therefore, it is necessary to incorporate these insights in the problem formulation $^{28}$.

\footnotetext{
${ }^{1}$ Fitness value is a term that is used for the value of objective function in the genetic algorithm and refers to the law of survival of the fittest.
} 


\section{Please cite the following article at:}

Sharifzadeh M, Rashtchian D, Pishvaie MR, Thornhill NF, (2011). Energy induced separation network synthesis of an olefin compression section: a case study. Industrial \& Engineering Chemistry Research, 50 (3), 1610-1623, (Link).

In this superstructure construction, the following judgments and insights are considered (Figure 4 and Figure 5):

- The superstructure does not permit any unit operation with a fixed packing bed upstream of the multistage compressor due to the detrimental erosion effects.

- A negative pressure gradient is the necessary condition for the flow of a fluid. Therefore, the outlet pressure of a mixer is set equal to the lowest entering pressure.

- Detrimental effect of ice formation inhibits use of refrigerants. Cooling water is used as the cooling medium throughout the design, reflecting the common practice in olefin plants.

- The forward flow of condensates results in mixing a heavy already stripped condensate with a light condensate that is unfavorable to the separation task. In addition, the backward flow of gas increases internal gas circulation and results in mixing the compressed light gas with a heavy one, which is also unfavorable to the separation target. The countercurrent flow of gas and liquid will result in the heavier phases flowing to the left side of the flowsheet and lighter phases flowing to the right side, shown in Figure 4.

- Considering the possibility of formation of a second aqueous phase, vapor-liquid-liquidequilibrium calculation is performed.

- The use of cooling water as coolant requires the overhead condensates in the distillation to have a temperature equal to or higher than recycling liquid condensates. The reason of this observation is that the recycling condensates will flash and may become colder than the cooling media. Therefore, the upper rectifier section of the distillation tower is 


\section{Please cite the following article at:}

Sharifzadeh M, Rashtchian D, Pishvaie MR, Thornhill NF, (2011). Energy induced separation network synthesis of an olefin compression section: a case study. Industrial \& Engineering Chemistry Research, 50 (3), 1610-1623, (Link).

eliminated and the column will be a stripper only.

- Throttling is not considered in this work, since it is unfavorable to the compression task because of its associated irreversibility. It is noteworthy that to avoid negative pressure in the model, pressure drop variables, if needed for EISEN synthesis to be defined, must satisfy an inequality constraint such as equation (3) to guarantee that estimated value of pressure will be less than the upstream pressure and the negative pressure requirement of flow will be met.

$$
\begin{aligned}
& \frac{P^{\text {outlet }}}{P^{\text {inlet }}}=P^{d v l p} \\
& P^{d v l p}<P^{\text {Throt }}
\end{aligned}
$$

- The produced shaft work by the turbine must meet the power consumption of the multistage compressor. In this research, mechanical losses in the shaft power transfer assumed to be negligible. The actual efficiency of the compression stage must be provided by vendors with manufacturing tests. In this research, the efficiencies are assumed at the fixed value of $76 \%$, suggested by Walas ${ }^{19}$.

- A destructive approach is applied to optimize the number of compression stages, as will be discussed in the next section.

\subsubsection{The number of compression stages and the pressure ratios}

The number of compression stages $\left(n^{c}\right)$ is a synthesis variable for the process configuration of the compressor section. In order to find the optimum value of this variable, the superstructure is constructed for a reasonable upper bound of $n^{c}$ (assumed to be $\max \left(n^{c}\right)=7$ ) and the lower 


\section{Please cite the following article at:}

Sharifzadeh M, Rashtchian D, Pishvaie MR, Thornhill NF, (2011). Energy induced separation network synthesis of an olefin compression section: a case study. Industrial \& Engineering Chemistry Research, 50 (3), 1610-1623, (Link).

bounds of pressure ratios are set to the hypothetical value of unity in the inequality (4), where equation (5) defines the dimensionless pressure ratio $P_{i}^{\text {ratio }}$ :

$$
1 \leq P_{i}^{\text {ratio }}
$$

$P_{i}^{\text {outlet }}=P_{i}^{\text {inlet }} \times P_{i}^{\text {ratio }}$

The compression ratio of unity can be interpreted as a redundant compression stage. However, the practical value of a compression ratio is restricted to the turndown ratio of the multistage compressor and is about 1.4. Therefore, if the optimal value of any of the pressure ratios falls below this practical value, it can be interpreted that $n^{c}$ must be reduced by one, and a new superstructure must be constructed. This is a destructive approach. On the other hand, use of too few compression stages will result in violation of the temperature constraints as the result of increased pressure ratios. Therefore, it is wise to seek a lower bound on $n^{c}$ and to enumerate $n^{c}$ for a feasible range, which was found to be from $n^{c}=4$ to $n^{c}=7$. However, the nonlinear nature of the problem poses a difficulty because optimizing the network for several configurations and then comparing the optimal designs for each value of $n^{c}$ does not guarantee the global optimum solution. The reason is that each of the enumerations is itself nonlinear and it can easily happen that one is comparing the global optimum of one enumeration with a local optimum of another. Nevertheless, an optimal value of compression ratio near unity is a signal for designer to rerun the superstructure optimization with less compression stages.

\subsubsection{The temperature constraints}

Beside the fact that the lower bound of each pressure ratio is limited by the practical value of the fabricated compressors, its highest value is also bounded by the maximum allowable temperature 


\section{Please cite the following article at:}

Sharifzadeh M, Rashtchian D, Pishvaie MR, Thornhill NF, (2011). Energy induced separation network synthesis of an olefin compression section: a case study. Industrial \& Engineering Chemistry Research, 50 (3), 1610-1623, (Link).

due to the risk of deposit formation, as discussed in the Section 3. Therefore, the maximum pressure ratio inequality (6) must satisfy the maximum temperature constraint given in inequality (7) implicitly. They are related to each other by the isentropic equation (8).

$P_{i}^{\text {ratio }} \leq P_{\max }^{\text {ratio }}$

$T_{i}^{\text {inlet }} \leq T^{\max }$

$\left(T_{i}^{\text {outlet }} / T_{i}{ }^{\text {inlet }}\right)=\left(P_{i}^{\text {outlet }} / P_{i}{ }^{\text {inlet }}\right)^{(\gamma / \gamma-1)} \times \lambda$

The coefficient $\lambda$ in equation (8) represents the irreversibility and is greater than unity. In this case study $T^{\max }$ is assumed to be $85^{\circ} \mathrm{C}$. Since the composition of cracked gas changes significantly as the network is being optimized, the corresponding $\gamma$-values are subject to uncertainty and it is not possible to construct a predetermined condensation trajectory known as the temperature path $^{16}$. Therefore, the upper bounds of the pressure ratios are set beyond the temperature constraints $\left(P_{\max }^{\text {ratio }}=3.2\right)$. Then by the model convergence, the extents of violation of the temperature constraints (equation (7)) are added to the objective value through a penalty function.

\subsubsection{The target pressure constraint}

Compression of cracked gas up to the required pressure (i.e., $P^{\text {final }}$ ) imposes another nonlinear constraint for pressure ratio, which also must be satisfied by the penalty function.

$$
P^{\text {init ¥ial }} \times \prod_{i=1}^{n_{c}} P_{i}^{\text {ratio }}=P^{\text {final }}
$$




\section{Please cite the following article at:}

Sharifzadeh M, Rashtchian D, Pishvaie MR, Thornhill NF, (2011). Energy induced separation network synthesis of an olefin compression section: a case study. Industrial \& Engineering Chemistry Research, 50 (3), 1610-1623, (Link).

However, while the optimization process is running, the suggested value of the $P^{\text {final }}$ may differ significantly from the desired exit pressure. This in turn affects the condensation rate in the mathematical model and may bias the optimization evolution, because the optimization variables interact. This difficulty is overcome by scaling the transferring values from the optimizer to the model, so the exit pressure is fixed to the desired value $\left(P^{f i n a l}=36.9^{\text {bar }}\right.$ in this case study) and the stage pressure ratios are being optimized in a feasible region. Before satisfaction of constraint (9) the trial value of cracked gas pressure that is leaving the system, is equal to $P^{\text {trial }}$ as follow:

$$
P^{\text {initial }} \times \prod_{i=1}^{n_{c}} P_{i}^{\text {ratio }}=P^{\text {trial }}
$$

The value of $P^{\text {trial }}$ must meet the desired exit pressure of compression section $P^{\text {final }}$ :

$$
\begin{array}{r}
P^{\text {trial }} \times \operatorname{Rdev}^{n_{c}}=P^{\text {final }} \\
\text { Rdev }=\left(P^{\text {final }} /_{P^{\text {trial }}}\right)^{1 / n_{c}}
\end{array}
$$

Where Rdev represents the deviation of $P^{\text {trial }}$ from the desired $P^{\text {final }}$. Therefore, the current values of pressure ratios from the optimizer are adjusted to compensate this deviation before transferring to the mathematical model:

$$
P_{i}^{\text {outlet }}=P^{\text {initial }} \times \prod_{w=1}^{i} P_{w}^{\text {ratio }} \times R d e v^{w}
$$

\subsubsection{Other constraints}

Another set of constraints concerns the maximum flow velocity and fouling limitations of the heat exchanger that will bound the minimum allowable approach temperature of the intercoolers: 


\section{Please cite the following article at:}

Sharifzadeh M, Rashtchian D, Pishvaie MR, Thornhill NF, (2011). Energy induced separation network synthesis of an olefin compression section: a case study. Industrial \& Engineering Chemistry Research, 50 (3), 1610-1623, (Link).

$$
\left(T_{i}^{\text {outlet }}-T_{C W}^{\text {inlet }}\right) \geq \Delta T^{\text {min }}
$$

Figure 5 depicts the two-stage turbine, where HHPS is consumed in the backpressure stage and the HPS is consumed in the condensing stage. Assuming that needed power in the multistage compressor is calculated first ( $H^{c o m p}$ is known), the produced shaft work of the turbine must meet power requirements of the multistage compressor leading to:

$$
H^{b c k p}\left(F^{H H P S}\right)+H^{c o n d}\left(F^{H P S}\right)=H^{\text {comp }}
$$

The material balance around control volumes depicted in Figure 5 by dotted closed lines, gives the following mass balance equations.

$$
\begin{aligned}
& F^{H H P S}+F^{H H P S-O U T}=F^{H H P S-I N} \\
& F^{H P S-I N}=F^{H H P S-O U T}+F^{B F W} \\
& F^{H P S-I N}+F^{H H P S}=F^{H P S-O U T}+F^{H P S} \\
& F^{H H P S-I N}+F^{B F W}=F^{H P S-O U T}+F^{H P S}
\end{aligned}
$$

The equations 14-18 in addition to the energy balance around a desuperheater, equation (19), comprise a set of six equations with seven variables and therefore one degree of freedom remains for the optimization.

$$
H^{H H P S-O U T}\left(F^{H H P S-O U T}\right)+H^{B F W}\left(F^{B F W}\right)=H^{H P S-I N}\left(F^{H P S-I N}\right)
$$

The above degree of freedom analysis explains that in the turbine section one processes variables can be selected as optimization variable. In this case study, the HHPS flow to the first stage of 
Please cite the following article at:

Sharifzadeh M, Rashtchian D, Pishvaie MR, Thornhill NF, (2011). Energy induced separation network synthesis of an olefin compression section: a case study. Industrial \& Engineering Chemistry Research, 50 (3), 1610-1623, (Link).

the turbine $F^{H H P S}$ is selected as the optimization variable.

\subsubsection{Optimization variables for mass integration of the olefin compression section}

The vector of synthesis variables $\mathbf{x}_{j, l}$ declares that the condensate from the $j^{\text {th }}$ equilibrium stage (source) will route to $l^{\text {th }}$ sink, which can be either one of the previous equilibrium stages or the stripper tower. Therefore, dissolved light gases have the opportunity to be stripped in the upstream stages before recycling through the whole network.

In this case study a continuous optimization method is employed. Therefore, integer values must be constructed from the continuous quantities of $\mathbf{x}_{j, l}$ variables as follows.

Firstly, the split ratios of condensate in the $j^{\text {th }}$ source are relaxed to nonzero continuous values $\mathbf{x}_{j, l}$, which decides what fraction of the condensate of source $j$ will route to sink $l$. The sum of values of $x_{j, l}$ for each source $j$ must be unity imposing the equality constraint (20). In addition, equality constraint (21) forces the multiplication of each two variable $x_{j, l}$ to be equal to zero. By satisfaction of these constraints, one of the continuous variables receives an integer value of unity while the others will be zero. Although during the optimization, flows of the condensate streams in the model are nonzero, the implication of the equality constraints (20) and (21) is that by convergence of the optimizer, for each source $j$ only one stream can have a nonzero value of the flowrate.

$$
\begin{array}{lr}
\sum_{j=1}^{n_{c}} x_{j, l}=1 & j \in\left\{0 \ldots n_{c}\right\}, l \in\left\{1 \ldots\left(n_{c}+1\right)\right\} \\
x_{j, l 1} \times x_{j, l 2}=0 & x_{j, l} \in(0,1), l 1 \neq l 2
\end{array}
$$




\section{Please cite the following article at:}

Sharifzadeh M, Rashtchian D, Pishvaie MR, Thornhill NF, (2011). Energy induced separation network synthesis of an olefin compression section: a case study. Industrial \& Engineering Chemistry Research, 50 (3), 1610-1623, (Link).

$$
l 1, l 2<j
$$

The constraint (22) guarantees that condensate can route only in the reverse direction of the compressed gas. The above-mentioned considerations are common to almost all EISEN case studies.

\subsubsection{Constraint handling}

In this research a constrained real-valued genetic algorithm (compared to binary-valued genetic algorithm) is used as the method of optimization. However, the constraints are satisfied using the method of penalty functions rather than method of death penalty. In a death penalty approach, an infeasible solution will be eliminated from the population. By contrast, in the penalty approach, a weighted sum of violations of the constraints will be added to the objective function. While the optimizer is trying to minimize the value of the objective function, it has to reduce the violation of constraints and by the convergence of the optimization the constraints are satisfied. The death penalty approach has the disadvantage of potential elimination of promising solutions with minor infeasibility, and therefore, is more likely to fall into local traps, and also has relatively larger number of required evolutions for convergence. For comparison in the original constrained GA, implementation of death penalty method (in which infeasible individuals are simply eliminated from population) may result in cases, in which a poor feasible solution may hinder the optimizer from investigating the whole search area and the program must wait for a very lucky mutation for further exploration. However, the price of using the penalty function method is the difficulty of precise evaluation of constraint violations.

The strategy to handle integer variables was twofold. The number of trays of stripper column are 


\section{Please cite the following article at:}

Sharifzadeh M, Rashtchian D, Pishvaie MR, Thornhill NF, (2011). Energy induced separation network synthesis of an olefin compression section: a case study. Industrial \& Engineering Chemistry Research, 50 (3), 1610-1623, (Link).

rounded to the nearest integer figure and sent to the simulation model for evaluation. However, the synthesis variables $\mathbf{x}_{j, l}$, which declare that the condensate from the $j^{\text {th }}$ equilibrium stage (source) will route to $l^{\text {th }}$ sink, are relaxed to have continuous values. Here, any condensate that is formed at the bottom of each inter-stage separator (see Figure 4) will be split between potential sinks. However, by the convergence of the optimization program, the constraints (20) and (21) are satisfied and only one of the potential sinks will receive the whole condensate of each stage, i.e., only one path is selected from the potential routing paths.

\subsection{Identifying the optimization variables}

As discussed above, the optimization variables can be classified into synthesis and operational variables. The types of the optimization variables are already identified as the objective functions and constraints for the optimization problem have been developed. These variables are shown in Table 2. The numbers of optimization variables of each type, is the subject of degree of freedom analysis in order to identify which variables are remained for optimization and are shown in the second column of Table 2.

\begin{tabular}{|c|c|l|}
\hline $\begin{array}{c}\text { Optimization } \\
\text { variables }\end{array}$ & number & \multicolumn{1}{|c|}{ Description } \\
\hline$n^{c}$ & 1 & Number of compression stages (synthesis optimization variable) \\
\hline$x_{j, l}$ & 34 & $\begin{array}{l}\text { Mass integration variable which decides whether condensate for the source } j \text { will flow to } \\
\text { the sink } l \text { (synthesis optimization variable) }\end{array}$ \\
\hline$P_{i}^{\text {ratio }}$ & 7 & Pressure ratio of the $i^{\text {th }}$ compression stage (operational optimization variable) \\
\hline$T_{i}^{\text {out }}$ & 7 & $\begin{array}{l}\text { Cracked gas exit temperature from intercooler at the } i^{\text {th }} \text { compression stage (operational } \\
\text { optimization variable) }\end{array}$ \\
\hline$n^{t}$ & 1 & number of stripper stages (synthesis optimization variable) \\
\hline$T^{\text {reboiler }}$ & 1 & Temperature in bottom of the stripper (operational optimization variable) \\
\hline$F^{\text {HHPS }}$ & 1 & HHPS flow to the turbine first stage (operational optimization variable) \\
\hline
\end{tabular}


Please cite the following article at:

Sharifzadeh M, Rashtchian D, Pishvaie MR, Thornhill NF, (2011). Energy induced separation network synthesis of an olefin compression section: a case study. Industrial \& Engineering Chemistry Research, 50 (3), 1610-1623, (Link).

Table 2. Optimization variables

\subsection{Implementation issues}

This section explains the programming techniques implemented in this research. Firstly, the structure of simulation-optimization programming is discussed, then the software tools used are presented and the parameters of optimization are reported.

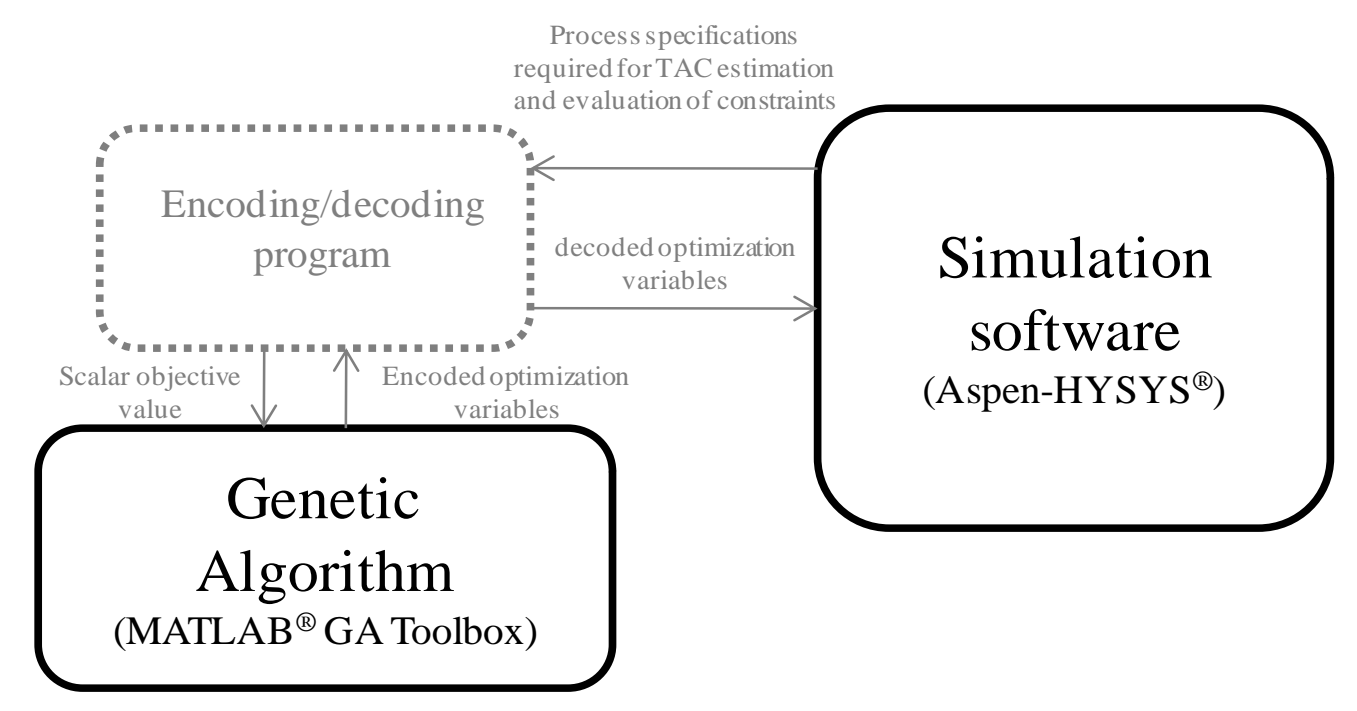

Figure 7. Simulation-optimization framework for EISENs.

\subsubsection{Programming structure and the employed software tools}

The overall flowchart of the simulation-optimization framework considered in this research is shown in Figure 7 and is presented below:

1. A superstructure was constructed for the olefin compression section. This superstructure provides the opportunities for selection of the optimum number of compression stages and treatment of condensing hydrocarbons. The alternative paths for treatment of light components dissolved in the condensates are included in the superstructure. These paths enable light gases to escape the liquid phase as they are being flashed in another stage 


\section{Please cite the following article at:}

Sharifzadeh M, Rashtchian D, Pishvaie MR, Thornhill NF, (2011). Energy induced separation network synthesis of an olefin compression section: a case study. Industrial \& Engineering Chemistry Research, 50 (3), 1610-1623, (Link).

with lower pressure or by going straightly to the distillation column. Then a simulation flowsheet for this superstructure was developed. In this article, Aspen HYSYS ${ }^{\circledR}$ was used for the simulation.

2. A mixed integer nonlinear optimization algorithm is formulated. The integer variables are responsible for the topology of the separation network. Depending on the current value of the optimization variables, the superstructure will be pruned and reduced to a feasible model of the process. Other continuous variables refer to the operating condition of this reduced model. In this case study, the MATLAB Genetic Algorithm (GA) toolbox is employed.

3. In this research, an intermediate code is programmed in MATLAB ${ }^{\circledR}$. This $m$-file ${ }^{\circledR}$ links GA $^{\circledR}$ toolbox to Aspen HYSYS ${ }^{\circledR}$ via the OLE automation ${ }^{30}$ (Figure 7). This framework assigns MATLAB $^{\circledR}$ as the client and Aspen HYSYS ${ }^{\circledR}$ as the server. This HYSYS simulation program models the superstructure. The intermediate program firstly receive the current value of the optimization variables and transfers them to the simulator. Then, it triggers the simulation solver. After model convergence, this code evaluates the objective value based on the solved model and reports this scalar value to the optimizer. Operating conditions include utility consumption rates and the required data for rating and sizing of the unit operations. This code also translates violation of the constraint to a scalar penalty value to be added to the objective function.

\subsubsection{Numerical values of the parameters}

In this case study, references ${ }^{23-25}$ provide data for determination of total annualized costs, 


\section{Please cite the following article at:}

Sharifzadeh M, Rashtchian D, Pishvaie MR, Thornhill NF, (2011). Energy induced separation network synthesis of an olefin compression section: a case study. Industrial \& Engineering Chemistry Research, 50 (3), 1610-1623, (Link).

including the equipment fixed costs, utility operating costs and product prices. Composition of entering cracked gas in addition to its flow rates, pressure and temperature are listed in the second column of Table 3. Table 4 gives the operating condition of cooling water used in intercooler and condensing stage and supply condition of HHPS and HPS steam levels to the backpressure and the condensing turbine stages. The applied equation of state is from KabadiDanner $^{26}$.

\begin{tabular}{l|c|c|c}
\hline & $\begin{array}{l}\text { Inlet Cracked gas to the } \\
\text { compression section }\end{array}$ & $\begin{array}{l}\text { Pyrolysis Gasoline of } \\
\text { ARPC® }\end{array}$ & $\begin{array}{l}\text { Pyrolysis Gasoline of } \\
\text { Synthesized Process }\end{array}$ \\
\hline Flow rate $[\mathrm{kg} / \mathrm{h}]$ & 85556.0 & 8057.0 & 8267.0 \\
\hline Temperature $\left[{ }^{\circ} \mathrm{C}\right]$ & 12.0 & 95.4 & 104 \\
\hline Pressure $[\mathrm{bar}(\mathrm{abs})]$ & 1.2 & 1.4 & 0.4 \\
\hline $\mathrm{H} 2[\mathrm{~kg} / \mathrm{h}]$ & 1016.0 & 0.0 & 0.0 \\
\hline CO $[\mathrm{kg} / \mathrm{h}]$ & 11.5 & 0.0 & 0.0 \\
\hline $\mathrm{CO} 2[\mathrm{~kg} / \mathrm{h}]$ & 6.8 & 0.0 & 0.0 \\
\hline H2S $[\mathrm{kg} / \mathrm{h}]$ & 34.7 & 0.0 & 0.0 \\
\hline Methane $[\mathrm{kg} / \mathrm{h}]$ & 15358.3 & 0.0 & 0.0 \\
\hline Acetylene $[\mathrm{kg} / \mathrm{h}]$ & 760.0 & 0.0 & 0.0 \\
\hline Ethylene $[\mathrm{kg} / \mathrm{h}]$ & 30990.7 & 0.0 & 0.0 \\
\hline Ethane $[\mathrm{kg} / \mathrm{h}]$ & 5372.8 & 0.0 & 0.0 \\
\hline Methyl Acetylene $[\mathrm{kg} / \mathrm{h}]$ & 607.9 & 0.0 & 0.0 \\
\hline Propadien $[\mathrm{kg} / \mathrm{h}]$ & 390.7 & 0.0 & 0.0 \\
\hline Propylene $[\mathrm{kg} / \mathrm{h}]$ & 11284.0 & 0.0 & 0.0 \\
\hline Propane $[\mathrm{kg} / \mathrm{h}]$ & 468.3 & 0.0 & 0.0 \\
\hline Vinyl Acetylene $[\mathrm{kg} / \mathrm{h}]$ & 176.7 & 5.9 & 0.0 \\
\hline $1-3$ Butadiene $[\mathrm{kg} / \mathrm{h}]$ & 3552.4 & 19.5 & 0.0 \\
\hline Butene $[\mathrm{kg} / \mathrm{h}]$ & 2518.5 & 7.2 & 0.0 \\
\hline Butane $[\mathrm{kg} / \mathrm{h}]$ & 256.3 & 1.4 & 0.0 \\
\hline C5+ $[\mathrm{kg} / \mathrm{h}]$ & 12044.4 & 8023.0 & \\
\hline H2O $[\mathrm{kg} / \mathrm{h}]$ & 705.7 & 0.0 & \\
\hline
\end{tabular}

Table 3. Cracked gas inlet stream conditions (second column). Pyrolysis gasoline stream conditions are compared for the synthesized process and in-operation $\mathrm{ARPC}^{\circledR}$ plant (third and fourth column). 
Please cite the following article at:

Sharifzadeh M, Rashtchian D, Pishvaie MR, Thornhill NF, (2011). Energy induced separation network synthesis of an olefin compression section: a case study. Industrial \& Engineering Chemistry Research, 50 (3), 1610-1623, (Link).

\begin{tabular}{ccc} 
& Supply T $\left({ }^{\circ} \mathrm{C}\right)$ & Supply P (bar) \\
\hline HHPS & 520 & 120 \\
\hline HPS & 410 & 40 \\
\hline Cooling Water & 25 & 7
\end{tabular}

Table 4. Cooling water and steam level conditions in the compression section

\subsubsection{Parameters of the genetic algorithm}

Table 5 gives the parameters used in the MATLAB ${ }^{\circledR}$ GA Toolbox. The population size was selected to be 35 in order to improve diversity in the population. The termination criteria of 50 stall generation was large enough to let the algorithm explore the feasible space of the nonlinear problem. Since two programs, i.e., GA toolbox and HYSYS are going to be synchronized and run together; the run time of program does not provide significant information. For example to make the program more robust, a code was programmed to monitor and check for convergence of the simulator, and the result of each generation is saved to avoid the need for restarting the program when calculation of the simulator fails. These strategies made the run time for the simulation longer. The run time is about 1-2 days for GA to converge.

\begin{tabular}{|l|l|}
\hline GA specification & Type of method or value of the parameter \\
\hline Optimization variables & The number of optimization variables was 52 (See Table 2.) \\
\hline Population size & 35 \\
\hline
\end{tabular}


Please cite the following article at:

Sharifzadeh M, Rashtchian D, Pishvaie MR, Thornhill NF, (2011). Energy induced separation network synthesis of an olefin compression section: a case study. Industrial \& Engineering Chemistry Research, 50 (3), 1610-1623, (Link).

\begin{tabular}{|l|l|}
\hline Initial population & $\begin{array}{l}\text { Different initial populations including random combinations of upper and lower bounds of } \\
\text { variables are used in order to improve probability of global solution determination. }\end{array}$ \\
\hline Mutation method & Gaussian \\
\hline Crossover function & Scattered \\
\hline Termination criteria & The fitness value has been stalled for 50 generation \\
\hline
\end{tabular}

Table 5. Specifications of GA algorithm used in this case study

\section{Results and discussion}

The result of superstructure optimization and the optimized network configuration are presented in this section. In addition, a comparison between existing industrial process and the synthesized process is made.

\subsection{Network feasible configurations}

As explained in the preceding sections, the destructive approach for superstructure optimization of the compression section was employed for $\max \left(n^{c}\right)=7$. The optimizer detected optimal pressure ratios less than 1.4 for $n^{c}=7$ and so the superstructure was adjusted to $n^{c}=6$ which is the optimum number of compression stages verified by optimization-simulation framework. However, for comparison the superstructures for $n^{c}=4,5$ were enumerated and the objective functions are reported in the Table 6 . For $n^{c}=4$ the temperature constraints could not be met and any further reduction of the superstructure was therefore not considered. Thus, there are two sets of feasible optimum designs only for $n^{c}=5,6$, and of these, $n^{c}=6$ has a better value of the objective function. It is noteworthy that fixed costs cover only $15.34 \%$ of total annualized costs. This result arises because energy consumption is dominant in the economics of olefin 


\section{Please cite the following article at:}

Sharifzadeh M, Rashtchian D, Pishvaie MR, Thornhill NF, (2011). Energy induced separation network synthesis of an olefin compression section: a case study. Industrial \& Engineering Chemistry Research, 50 (3), 1610-1623, (Link).

compression. Since the economics are not very sensitive to fixed costs, the choice between five or six stages will depend on the reduced running costs offered by heat, mass and power integration, as discussed in the subsections below.

\begin{tabular}{|c|c|c|c|c|c|}
\hline $\begin{array}{c}\text { Number of } \\
\text { stages }\end{array}$ & $\begin{array}{c}\text { Total annualized } \\
\text { costs } \$ / \text { hour }\end{array}$ & $\begin{array}{c}\text { Fixed cost } \\
\$ / \text { hour }\end{array}$ & Fixed cost $\%$ & $\begin{array}{l}\text { HISEN fixed cost } \\
\$ / \text { hour }\end{array}$ & $\begin{array}{c}\text { HISEN fixed cost } \\
\% \\
\end{array}$ \\
\hline 4 & 972.45 & 120.86 & 12.33 & 27.36 & 2.79 \\
\hline 5 & 950.66 & 128.54 & 13.52 & 28.91 & 3.04 \\
\hline 6 & 930.94 & 142.80 & 15.34 & 29.25 & 3.14 \\
\hline 7 & 941.15 & 154.72 & 16.44 & 29.31 & 3.11 \\
\hline
\end{tabular}

Table 6. Operating/fixed costs values for the number of compression stages $n^{c}=4,5,6,7$

\subsection{Cooling task and its economic significance}

The approach temperature, where the two composite curves touch each other on the pinch diagram, is known to be the trade-off player between the fixed and operating costs of a heat exchanger. However in EISEN synthesis, approach temperature controls condensation rates and compositions, as well as cost trade-off. Increasing condensate formation decreases the gas flow rate to the next stage and also influences compositions of withdrawn phases, which affects mass integration. Table 7 shows that the lower bounds of most optimum approach temperatures (i.e., $10^{\circ} \mathrm{C}$ ) are active. The authors investigated the effects of lowering this boundary by $5^{\circ} \mathrm{C}$. Then the optimum number of the compression section would be $n^{c}=5$. This result signals that the number of compression stages has a tight relationship with cooling in compression sections. Design of a six stage compression system enhances the flexibility of process operation in confronting supplied utility fluctuations such as the temperature of supplied cooling water in different seasons. Also considering the fact that heat transfer efficiency will decrease over time suggests $n^{c}=6$ is a safer design. 
Please cite the following article at:

Sharifzadeh M, Rashtchian D, Pishvaie MR, Thornhill NF, (2011). Energy induced separation network synthesis of an olefin compression section: a case study. Industrial \& Engineering Chemistry Research, 50 (3), 1610-1623, (Link).

\begin{tabular}{|c|c|c|c|c|c|c|c|}
\hline \multirow[b]{2}{*}{$\begin{array}{l}\text { Number of } \\
\text { stages }\end{array}$} & \multicolumn{7}{|c|}{ Approach temperatures for } \\
\hline & 1st Stage & $\begin{array}{c}\text { 2nd } \\
\text { Stage }\end{array}$ & $\begin{array}{l}\text { 3rd } \\
\text { Stage }\end{array}$ & $\begin{array}{l}\text { 4th } \\
\text { Stage }\end{array}$ & $\begin{array}{l}\text { 5th } \\
\text { Stage }\end{array}$ & $\begin{array}{c}\text { 6th } \\
\text { Stage }\end{array}$ & $\begin{array}{c}\text { 7th } \\
\text { Stage }\end{array}$ \\
\hline 4 & 10.00 & 10.00 & 10.00 & 10.00 & ----- & ----- & ----- \\
\hline 5 & 10.00 & 10.00 & 10.00 & 10.00 & 12.50 & ----- & ------ \\
\hline 6 & 10.00 & 10.00 & 10.00 & 10.00 & 10.00 & 19.30 & ------ \\
\hline 7 & 10.00 & 10.00 & 10.00 & 10.00 & 10.00 & 10.00 & 19.17 \\
\hline
\end{tabular}

Table 7. Optimum approach temperature for enumerated $n^{c}=4,5,6,7$

\subsection{Power integration}

For incondensable gas compression, the rule of thumb for optimum pressure ratios, presented by many authors ${ }^{23,29}$, is that they are all the same and given by:

$$
P_{i}^{\text {ratio }}=\left(P^{\text {final }} / P^{\text {initial }}\right)^{1 / n_{c}}
$$

Table 8 shows, however, that the optimum pressure ratios are significantly higher in earlier stages. The physical reason for this result is that the higher pressure ratios in early stages separate condensate from the condensable gas as soon as possible, and hence reduce the required shaft work. This result also confirm that $n^{c}=6$ is superior to $n^{c}=5$ because in six stage compression system condensates are separated earlier at lower pressures than in a five stage system.

\begin{tabular}{|c|c|c|c|c|c|c|c|}
\hline \multirow[b]{2}{*}{$\begin{array}{l}\text { Number of } \\
\text { stages }\end{array}$} & \multicolumn{7}{|c|}{ Pressure ratios for: } \\
\hline & 1st stage & 2nd stage & $\begin{array}{c}\text { 3rd } \\
\text { stage }\end{array}$ & $\begin{array}{c}\text { 4th } \\
\text { stage }\end{array}$ & $\begin{array}{c}\text { 5th } \\
\text { stage }\end{array}$ & $\begin{array}{c}\text { 6th } \\
\text { stage }\end{array}$ & $\begin{array}{l}\text { 7th } \\
\text { stage }\end{array}$ \\
\hline 4 & 2.837 & 2.584 & 2.003 & 2.000 & ----- & ------ & ------ \\
\hline 5 & 2.677 & 1.901 & 1.834 & 1.719 & 1.830 & ------ & ------ \\
\hline 6 & 2.658 & 1.919 & 1.591 & 1.427 & 1.587 & 1.597 & ------ \\
\hline 7 & 2.062 & 1.720 & 1.792 & 1.410 & 1.554 & 1.501 & 1.405 \\
\hline
\end{tabular}

Table 8. Optimum pressure ratios for enumerated $n^{c}=4,5,6,7$

Power integration in the turbine stage suggests that all the HHPS must go through the turbine 


\section{Please cite the following article at:}

Sharifzadeh M, Rashtchian D, Pishvaie MR, Thornhill NF, (2011). Energy induced separation network synthesis of an olefin compression section: a case study. Industrial \& Engineering Chemistry Research, 50 (3), 1610-1623, (Link).

backpressure stage and then the rest of the required power by compressor is supplied by the condensing stage. The reasons behind the result are that steam must be desuperheated and then exported to the site HPS header, and mixing BFW and HHPS is thermodynamically unfavorable because of irreversibility of the mixing process.

\subsection{Mass integration effects on internal gas circulation}

Tower feed composition is to be optimized by means of mass integration. Table 9 shows the optimum condensate flow configuration for each enumerated number of compression stages, while Figure 4 shows the sink/source assignments. The configurations can be classified between two counteracting extremes: the countercurrent gas-liquid flows and total recycled gas-liquid flows. Table 10 compares these extremes with the optimum solution. It shows the optimum solution has less gas recycled from the tower and more internal gas circulation in the compressor stages than the total recycle flow solution. By contrast, the optimum solution has less internal gas circulation in the compressor stages than the countercurrent flow solution, but more gas recycled from the tower. Again $n^{c}=6$ provides more sources for mass integration.

\begin{tabular}{l}
$\begin{array}{c}\text { Number of } \\
\text { stages }\end{array}$ \\
\hline 4 \\
\hline 5 \\
\hline 6 \\
\hline 7 \\
\hline
\end{tabular}

Source\#1 Source\#2 Source\#3 Source\#4 Source\#5 $\quad$ Source\#6 Source\#7 $\quad$ Source\#8

\begin{tabular}{|c|c|c|c|c|c|c|c|c|}
\hline Sink \# & 1 & 2 & 3 & 3 & 5 & --- & --- & --- \\
\hline Sink \# & 1 & 2 & 3 & 4 & 1 & 6 & --- & --- \\
\hline Sink \# & 1 & 2 & 3 & 1 & 1 & 6 & 7 & --- \\
\hline Sink \# & 1 & 2 & 1 & 4 & 5 & 6 & 7 & 8 \\
\hline
\end{tabular}

Table 9. Optimum sink/source configuration for enumerated $n^{c}=4,5,6,7$ (referring to Figure 4 superstructure)

\begin{tabular}{|c|c|c|c|c|c|c|c|c|}
\hline & $\begin{array}{c}\text { Total } \\
\cos \$ / h\end{array}$ & $\begin{array}{c}\text { stripper } \\
\text { overhead } \\
(\mathrm{kg} / \mathrm{h})\end{array}$ & $\begin{array}{c}\text { 1st } \\
\text { discharge } \\
(\mathrm{kg} / \mathrm{h})\end{array}$ & $\begin{array}{c}\text { 2nd } \\
\text { discharge } \\
(\mathrm{kg} / \mathrm{h})\end{array}$ & $\begin{array}{c}\text { 3rd } \\
\text { discharge } \\
(\mathrm{kg} / \mathrm{h})\end{array}$ & $\begin{array}{c}\text { 4th } \\
\text { discharge } \\
(\mathrm{kg} / \mathrm{h})\end{array}$ & $\begin{array}{c}\text { 5th } \\
\text { discharge } \\
(\mathrm{kg} / \mathrm{h})\end{array}$ & $\begin{array}{c}\text { 6th } \\
\text { discharge } \\
(\mathrm{kg} / \mathrm{h})\end{array}$ \\
\hline Total recycle & 941.8 & 1993.85 & 84812 & 84800 & 82497 & 80099 & 78439 & 76651 \\
\hline Mass integrated & 934.2 & 1559.4 & 84567 & 86074 & 82908 & 80123 & 78670 & 76651 \\
\hline Countercurrent & 961 & 202 & 84922 & 87733 & 84620 & 81379 & 79526 & 77111 \\
\hline
\end{tabular}


Please cite the following article at:

Sharifzadeh M, Rashtchian D, Pishvaie MR, Thornhill NF, (2011). Energy induced separation network synthesis of an olefin compression section: a case study. Industrial \& Engineering Chemistry Research, 50 (3), 1610-1623, (Link).

Table 10. Economical comparison between optimal mass integration and extreme patterns of condensate flow.

\subsection{Comparison between the existing and the synthesized flowsheets}

The flowsheet of the existing compression section from a real olefin plant is shown in Figure 3. This flowsheet utilizes countercurrent flow of the cracked gas and the condensates. The flowsheet of the synthesized compression sections is shown in Figure 8. This flowsheet, by contrast to the existing flowsheet, is somewhat between total recycling directly to stripper and countercurrent flow. In addition, the synthesized flowsheet also utilizes the knock-out drum (first separator in the figure 3 and 8 ) to strip the condensates before routing to stripper. 
Please cite the following article at:

Sharifzadeh M, Rashtchian D, Pishvaie MR, Thornhill NF, (2011). Energy induced separation network synthesis of an olefin compression section: a case study. Industrial \& Engineering Chemistry Research, 50 (3), 1610-1623, (Link).

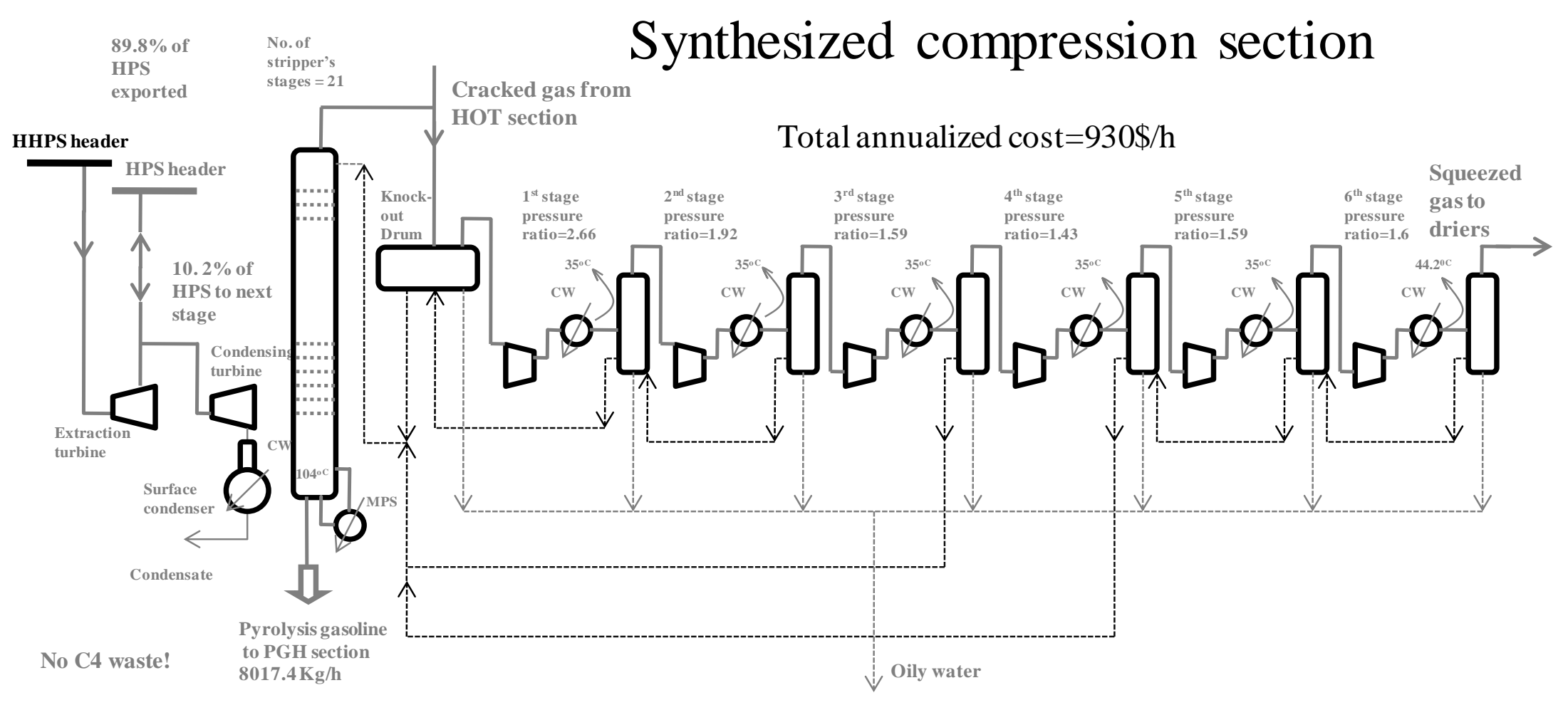

Figure 8. Optimum solution of olefin compressor section synthesis task. 
Please cite the following article at:

Sharifzadeh M, Rashtchian D, Pishvaie MR, Thornhill NF, (2011). Energy induced separation network synthesis of an olefin compression section: a case study. Industrial \& Engineering Chemistry Research, 50 (3), 1610-1623, (Link).

The operational conditions of the two flowsheets are reported in Table 3 and 11. The second column of Table 3 reports the entering composition of cracked gas to the compression section. Table 3 also presents the composition of the exiting pyrolysis gasoline of the synthesized process compared with existing design from Arak Petrochemical Company (ARPC $\left.{ }^{\circledR}\right)$. This comparison has two interesting features. Firstly, slightly more pyrolysis gasoline is separated in the synthesized flowsheet and secondly the separated pyrolysis gasoline contains a very negligible amount of $\mathrm{C}_{3}$ and $\mathrm{C}_{4}$ components, leading to conclusions that the rigorous optimization approach improves the sharpness of the separation. In the both designs, minimizing the approach temperatures is favorable and temperature constraints are active to reduce the temperature of cracked gas before entering the next compression stage. Pressure ratios, inlet-outlet temperatures of cracked gas in each compressor, and also flowrates of cracked gas into and condensates from each compression section are given in the Table 11. 
Please cite the following article at:

Sharifzadeh M, Rashtchian D, Pishvaie MR, Thornhill NF, (2011). Energy induced separation network synthesis of an olefin compression section: a case study. Industrial \& Engineering Chemistry Research, 50 (3), 1610-1623, (Link).

\begin{tabular}{|c|c|c|}
\hline & Existing & Synthesized \\
\hline Pressure ratio (1st stage) & 2.67 & 2.66 \\
\hline Pressure ratio (2nd stage) & 2.00 & 1.92 \\
\hline Pressure ratio (3rd stage) & 1.96 & 1.59 \\
\hline Pressure ratio (4th stage) & 1.94 & 1.43 \\
\hline Pressure ratio (5th stage) & 1.83 & 1.59 \\
\hline Pressure ratio (6th stage) & --- & 1.60 \\
\hline Inlet temperature of cracked gas into 1 st stage $\left[{ }^{\circ} \mathrm{C}\right]$ & 12.0 & 12.4 \\
\hline Inlet temperature of cracked gas into $2 \mathrm{nd}$ stage $\left[{ }^{\circ} \mathrm{C}\right]$ & 29.0 & 31.2 \\
\hline Inlet temperature of cracked gas into $3 \mathrm{rd}$ stage $\left[{ }^{\circ} \mathrm{C}\right]$ & 33.5 & 35.0 \\
\hline Inlet temperature of cracked gas into 4 th stage $\left[{ }^{\circ} \mathrm{C}\right]$ & 34.2 & 35.0 \\
\hline Inlet temperature of cracked gas into 5 th stage $\left[{ }^{\circ} \mathrm{C}\right]$ & 35.0 & 34.5 \\
\hline Inlet temperature of cracked gas into 6 th stage $\left[{ }^{\circ} \mathrm{C}\right]$ & --- & 35.0 \\
\hline Outlet temperature of cracked gas from 1 st stage $\left[{ }^{\circ} \mathrm{C}\right]$ & 85.0 & 84.9 \\
\hline Outlet temperature of cracked gas from 2 nd stage $\left[{ }^{\circ} \mathrm{C}\right]$ & 81.1 & 82.9 \\
\hline Outlet temperature of cracked gas from 3 rd stage $\left[{ }^{\circ} \mathrm{C}\right]$ & 84.2 & 72.1 \\
\hline Outlet temperature of cracked gas from 4 th stage $\left[{ }^{\circ} \mathrm{C}\right]$ & 85.8 & 63.6 \\
\hline Outlet temperature of cracked gas from 5 th stage $\left[{ }^{\circ} \mathrm{C}\right]$ & 83.8 & 71.8 \\
\hline Outlet temperature of cracked gas from 6 th stage $\left[{ }^{\circ} \mathrm{C}\right]$ & --- & 73.5 \\
\hline Flowrate of cracked gas into 1 st stage $[\mathrm{Kg} / \mathrm{h}]$ & 85950 & 84567 \\
\hline Flowrate of cracked gas into 2 nd stage $[\mathrm{Kg} / \mathrm{h}]$ & 86636 & 86074 \\
\hline Flowrate of cracked gas into 3 rd stage $[\mathrm{Kg} / \mathrm{h}]$ & 84773 & 82908 \\
\hline Flowrate of cracked gas into 4 th stage $[\mathrm{Kg} / \mathrm{h}]$ & 80638 & 80123 \\
\hline Flowrate of cracked gas into 5th stage $[\mathrm{Kg} / \mathrm{h}]$ & 77611 & 78670 \\
\hline Flowrate of cracked gas into 6 th stage $[\mathrm{Kg} / \mathrm{h}]$ & --- & 76651 \\
\hline Flowrate of condensate from knock out drum $[\mathrm{Kg} / \mathrm{h}]$ & 0 & 3950 \\
\hline Flowrate of condensate from 1 st stage $[\mathrm{Kg} / \mathrm{h}]$ & 8451 & 1481 \\
\hline Flowrate of condensate from 2 nd stage $[\mathrm{Kg} / \mathrm{h}]$ & 9805 & 2985 \\
\hline Flowrate of condensate from $3 \mathrm{rd}$ stage $[\mathrm{Kg} / \mathrm{h}]$ & 7944 & 2633 \\
\hline Flowrate of condensate from 4 th stage $[\mathrm{Kg} / \mathrm{h}]$ & 3691 & 4592 \\
\hline Flowrate of condensate from 5 th stage $[\mathrm{Kg} / \mathrm{h}]$ & 2824 & 3421 \\
\hline Flowrate of condensate from 6 th stage $[\mathrm{Kg} / \mathrm{h}]$ & --- & 1943 \\
\hline Temperature of stripper (bottom) $\left[{ }^{\circ} \mathrm{C}\right]$ & 95.4 & 104 \\
\hline Temperature of stripper (top) $\left[{ }^{\circ} \mathrm{C}\right]$ & 41 & 41.9 \\
\hline Number of trays in stripper & 16 & 21 \\
\hline Approach temperature in the 1st stage & 10 & 10 \\
\hline Approach temperature in the 2 nd stage & 10 & 10 \\
\hline Approach temperature in the 3 rd stage & 10 & 10 \\
\hline Approach temperature in the 4 th stage & 10 & 10 \\
\hline Approach temperature in the 5th stage & 10 & 10 \\
\hline Approach temperature in the 6th stage & 10 & 19.2 \\
\hline
\end{tabular}

Table 11. Comparison between existing and synthesized compression section 
Please cite the following article at:

Sharifzadeh M, Rashtchian D, Pishvaie MR, Thornhill NF, (2011). Energy induced separation network synthesis of an olefin compression section: a case study. Industrial \& Engineering Chemistry Research, 50 (3), 1610-1623, (Link).

\subsection{Optimum synthesis of olefin compression section}

The synthesized olefin compression section is shown in Figure 8 with all optimal values for the variables. The targets from Section 3.2.5 have been met in this research as follows:

- The application of rigorous mathematical calculation has guaranteed the accuracy and precision of the nonideal mixture and nonlinear process calculations in the synthesized EISEN. Therefore, the synthesized process can be passed to further stages of design such as equipment sizing, rating and procurement. (target 1)

- As discussed in Sections 5.2 to 5.4, the optimizer successfully captured the interactions of mass, heat and power integrations with each other (target 2). The work also has provided an explanation for why six compression stages are superior from cost and operational perspectives (target 3).

- The optimum nonsharp extent of separation is determined by optimizer and depicts the trade-off between the opposing compression and condensation tasks.

- An economical overview of different aspects of olefin compression section has been constructed as discussed in Sections 5.1-5.2. (target 4). 


\section{Please cite the following article at:}

Sharifzadeh M, Rashtchian D, Pishvaie MR, Thornhill NF, (2011). Energy induced separation network synthesis of an olefin compression section: a case study. Industrial \& Engineering Chemistry Research, 50 (3), 1610-1623, (Link).

Table 12 shows how the olefin compression study has met the EISEN challenges laid down by Dunn and El-Halwagi ${ }^{6}$, which were outlined in Section 2.2. This table shows that the methods presented in the paper for applying EISEN synthesis to an olefin compression section is able to address the challenges in a systematic way and to provide answers for the key questions posed by those authors.

\begin{tabular}{|c|c|}
\hline $\begin{array}{l}\text { Challenges from Dunn and El-Halwagi }{ }^{6} \text { for } \\
\text { ESIEN synthesis problem }\end{array}$ & $\begin{array}{l}\text { Simulation-optimization framework for Olefin compression } \\
\text { section }\end{array}$ \\
\hline $\begin{array}{l}\text { Which energy separating agents should be } \\
\text { employed? }\end{array}$ & $\begin{array}{l}\text { The optimizer synthesized the flowsheet of olefin compression } \\
\text { section, which employs cooling water in inter-stage coolers for } \\
\text { condensation of pyrolysis gasoline, medium pressure steam for } \\
\text { evaporation and separation of light dissolved components at } \\
\text { reboiler and cooling water for promoting the vacuum condition in } \\
\text { the surface condenser. }\end{array}$ \\
\hline $\begin{array}{l}\text { Should stream pressurization or } \\
\text { depressurization be employed and, if so, to } \\
\text { what level? }\end{array}$ & $\begin{array}{l}\text { Configuration and specification of the two-stage turbine and the } \\
\text { multi-stage compressor are synthesized and designed by the } \\
\text { optimization-simulation framework. }\end{array}$ \\
\hline $\begin{array}{l}\text { What is the optimal mass and heat load to be } \\
\text { removed/added by each ESA? }\end{array}$ & $\begin{array}{l}\text { The operational costs, including hot and cold utility usage, in } \\
\text { conjunction to the capital costs are optimized through the objective } \\
\text { function of total annualized costs. }\end{array}$ \\
\hline $\begin{array}{l}\text { How should the waste (separated } \\
\text { condensates) and ESA streams be matched } \\
\text { (i.e., stream pairings)? }\end{array}$ & $\begin{array}{l}\text { The optimizer has decided on the further treatment of separated } \\
\text { condensates as they are being flashed in a stage with lower } \\
\text { pressure or being sent to distillation column for striping. }\end{array}$ \\
\hline $\begin{array}{l}\text { What is the optimal system configuration (e.g } \\
\text {, how should the heat-induced separators, } \\
\text { heat exchangers and compressors/turbines be } \\
\text { arranged?, is there any stream splitting and } \\
\text { mixing? }\end{array}$ & $\begin{array}{l}\text { The optimizer has decided on the best configuration of the process } \\
\text { flowsheet through the superstructure. }\end{array}$ \\
\hline
\end{tabular}

Table 12. Achievements of the simulation-optimization framework in addressing the challenges of EISEN synthesize problem.

\section{Conclusion}

In this paper, a case study of the synthesis and design of an olefin compression section as an Energy Induced Separation Network (EISEN) is presented. The EISEN refers to a network of heat exchangers and also pressure-adjusting devices that realizes a separation target via latent 


\section{Please cite the following article at:}

Sharifzadeh M, Rashtchian D, Pishvaie MR, Thornhill NF, (2011). Energy induced separation network synthesis of an olefin compression section: a case study. Industrial \& Engineering Chemistry Research, 50 (3), 1610-1623, (Link).

heat exchange. The olefin compression section is a critical part of a production plant that cannot be classified by the end of pipe treatment or in-plant source reduction paradigms presented in earlier works ${ }^{11,13}$. As shown by the optimization results, the EISEN has a power integration dimension, in addition to mass integration and heat exchange. It is also shown how gradual condensation and nonsharp separation can be included in an optimization formulation. Considering intercoolers as the only heat-induced part of the multistage compressor network, the results show its importance for operational costs and network configuration by conducting condensation rate. From the financial results produced by the optimization, it can be concluded that process economy is dominated by operational costs. A consequence of this observation is that it suggests periodical reengineering and retrofitting of current processes if energy prices were anticipated to increase for a prolonged period. Referring to the literature ${ }^{6}$, any EISEN synthesis problem involves decision on usage of energy carrier streams (i.e. hot and cold utilities), pressure levels, and temperature points where condensate are being separated and the configuration of the network, which promote this separation task. In addition, the proposed solving methodology must respect the process constraints. All these characteristics are addressed in this research through a simulation-optimization programming for the case of olefin compression section. The presented simulation-optimization framework is applied properly, can also address other proprietary case studies.

Acknowledgement: The technical data has been obtained from Arak petrochemical co. $\left(\mathrm{ARPC}^{\circledR}\right)$ in Iran. The cooperation and accompanying help of ARPC is gratefully appreciated.

\section{Abbreviations}

EISENs $\quad$ Energy Induced Separation Network synthesis

BFW Boiler Feed Water 
Please cite the following article at:

Sharifzadeh M, Rashtchian D, Pishvaie MR, Thornhill NF, (2011). Energy induced separation network synthesis of an olefin compression section: a case study. Industrial \& Engineering Chemistry Research, 50 (3), 1610-1623, (Link).

$\begin{array}{ll}\text { HHPS } & \text { High High Pressure steam @ } 120^{\text {bar } \& 520{ }^{\circ} \mathrm{C}} \\ \text { HPS } & \text { High Pressure steam @ } 40^{\text {bar } \& 410^{\circ} \mathrm{C}} \\ \text { HISENs } & \text { Heat Induced Separation Network synthesis }\end{array}$

\section{Continuous optimization variables}

E [-] The set of NE Energy separating agents used by EISEN (Figure 1)

$F^{H H P S} \quad[\mathrm{~kg} / \mathrm{h}] \quad$ The flow of consumed HHPS in backpressure stage of turbine (Figure 5)

$F^{H H P S-I N} \quad[\mathrm{~kg} / \mathrm{h}] \quad$ The flow of HHPS supplied by hot section furnaces to turbine (Figure 5)

$F^{H H P S-O U T} \quad[\mathrm{~kg} / \mathrm{h}] \quad$ The flow of unconsumed portion of HHPS to superheater (Figure 5)

$F^{H P S} \quad[\mathrm{~kg} / \mathrm{h}] \quad$ The flow of consumed HPS in condensing stage of turbine (Figure 5)

$F^{H P S-I N} \quad[\mathrm{~kg} / \mathrm{h}] \quad$ The flow of HPS generated from excess HHPS desuperheating (Figure 5)

$F^{H P S-O U T} \quad[\mathrm{~kg} / \mathrm{h}] \quad$ The flow of excess HPS exported to the site header (Figure 5)

$F^{B F W} \quad[\mathrm{~kg} / \mathrm{h}] \quad$ The flow of BFW to desuperheater (Figure 5)

$H^{b c k p} \quad[\mathrm{~kW}] \quad$ The power which is generated by backpressure stage of turbine (Figure 5)

$H^{\text {cond }} \quad[\mathrm{kW}]$ The power which is generated by condensing stage of turbine (Figure 5)

$H^{\text {comp }} \quad[\mathrm{kW}]$ The power which is consumed by multistage compressor

$h^{\text {HHPS-OUT }} \quad[\mathrm{kJ}] \quad$ The enthalpy of HHPS entering the desuperheater

$h^{B F W} \quad[\mathrm{~kJ}] \quad$ The enthalpy of BFW entering the desuperheater

$h^{H P S-I N} \quad[\mathrm{~kJ}] \quad$ The enthalpy of HPS leaving the desuperheater

$L \quad[-] \quad$ The set of NL condensate streams leaving the EISEN (Figure 1)

$P^{d v l p} \quad[-] \quad$ The developed pressure ration of each compression stage

$P^{\text {Throt }} \quad[-] \quad$ The throttled pressure ration of each compression stage

$P_{i}{ }^{\text {outlet }} \quad[\mathrm{Pa}]$ The outlet pressure of gas from the $\mathrm{i}^{\text {th }}$ compression stage

$P_{i}^{\text {inlet }} \quad[\mathrm{Pa}] \quad$ The inlet pressure of gas to the $\mathrm{i}^{\text {th }}$ compression stage

$P_{i}^{\text {ratio }} \quad[-] \quad$ The pressure ratio of the $\mathrm{i}^{\text {th }}$ compression stage

$P_{\max }^{\text {ratio }} \quad[-] \quad$ The maximum pressure ratio limited by the max allowable temperature

$P^{\text {initial }} \quad[\mathrm{Pa}] \quad$ The supply pressure of gas at the network entry

$P^{\text {final }} \quad[\mathrm{Pa}] \quad$ The target pressure of gas at the network exit (36.9 ${ }^{\text {bar }}$ in this case study)

$P^{\text {trial }} \quad[\mathrm{Pa}] \quad$ Trial value for the exit pressure of the network

$R \quad[-] \quad$ The set of $N R$ rich streams entering the EISEN (Figure 1)

$R^{\prime} \quad[-] \quad$ The set of $N R^{\prime}$ rich streams leaving the EISEN (Figure 1)

Rdev [-] The deviation ratio of $P^{\text {trial }}$ from $P^{\text {final }}$ - must be one when the target pressure constraint is satisfied

$T_{i}{ }^{\text {outlet }} \quad\left[{ }^{\circ} \mathrm{C}\right] \quad$ The cracked gas exit temperature from intercooler at the $i^{\text {th }}$ compression stage.

$T_{C W}{ }^{\text {inlet }} \quad\left[{ }^{\circ} \mathrm{C}\right] \quad$ The inlet temperature of cooling water

$\Delta T^{\min } \quad\left[{ }^{\circ} \mathrm{C}\right] \quad$ The minimum temperature difference of gas and coolant

Integer optimization variables

$n^{c} \quad[-] \quad$ The total number of compression stages 
Please cite the following article at:

Sharifzadeh M, Rashtchian D, Pishvaie MR, Thornhill NF, (2011). Energy induced separation network synthesis of an olefin compression section: a case study. Industrial \& Engineering Chemistry Research, 50 (3), 1610-1623, (Link).

$n^{t} \quad[-] \quad$ The total number of stripper trays

$x_{j, l} \quad[-] \quad$ The mass integration variable which decide whether condensate for the source $j$ will flow to the sink $l$

\section{Parameters}

$\lambda \quad[-] \quad$ The coefficient multiplied to isentropic compression relation and accounts for the process irreversibility

$\gamma \quad[-] \quad$ The specific heat ratio for the cracked gas mixture

\section{Subscripts}

$i \quad$ Index of compression stages

$j \quad$ Index of the condensate (source) withdrawn at the $\mathrm{j}^{\text {th }}$ stage interstage separator

$l \quad$ Index of the sink that each source can rout to (considering the pressure gradient)

$w \quad$ Dummy variable 


\section{Please cite the following article at:}

Sharifzadeh M, Rashtchian D, Pishvaie MR, Thornhill NF, (2011). Energy induced separation network synthesis of an olefin compression section: a case study. Industrial \& Engineering Chemistry Research, 50 (3), 1610-1623, (Link).

\section{Literature cited:}

(1) Frangopoulos, C. A.; Spakovsky, M. R. von; Sciubba, E. A brief review of methods for the design and synthesis optimization of energy systems. Int. J. Applied Thermodynamics. 2002, 5(4): 151-160.

(2) Cerda, J.; Westerberg, A. W.; Mason, D. Linnhoff, B.; Minimum utility usage in heat exchanger network synthesis. Chem. Eng. Sci. 1983, 38: 373-87.

(3) Linnhoff, B.; Hindmarsh, E. The pinch design method for heat exchanger networks. Chem. Eng. Sci. 1983, 38: 745-63.

(4) El-Halwagi, M. M.; Manousiouthakis, V. Synthesis of mass exchange networks. AIChE J. 1989, 35(8): 1233-1244.

(5) El-Halwagi, M. M.; Manousiouthakis, V. Design and analysis of multi-component massexchange networks. AIChE Annual Meeting. San Francisco 1989.

(6) Dunn, R. F.; El-Halwagi, M. M. Process integration technology review: background and applications in the chemical process industry. J. Chem. Technol. Biotechnol. 2003, 78: 10111021, DOI: 10.1002/jctb.738.

(7) El-Halwagi, M. M. Pollution prevention through process integration. Clean Products and Processes. 1998, 1: 5-19.

(8) Dunn, R. F.; Bush, G. E. Using process integration technology for CLEANER production. Journal of Cleaner Production. 2001, 9: 1-23.

(9) El-Halwagi, M. M.; Garrison, G. W. Synthesis of waste interception and allocation network. AIChE J. 1996, 42(11): 3087-3101.

(10) El-Halwagi, M. M.; Srinivas, B. K.; Dunn, R. F. Synthesis of heat induced separation networks. Chem. Eng. Sci. 1995, 50: 81-97.

(11) Dunn, R. F.; Zhu, M; Srinivas, B. K.; El-Halwagi, M. M. Optimal design of energy-induced separation systems for VOC recovery. AIChE Symp. Ser. 1995, 90: 74-85.

(12) Dunn, R. F.; Srinivas, B.K. Synthesis of heat-induced waste minimization networks (HIWAMINs). Adv. Environ. Res. 1997, 1: 275-301.

(13) Dunn, R. F.; Hamad, A. A.; Dobson, A. M. Synthesis of energy-induced waste minimization networks (EIWAMINs) for simultaneous waste reduction and heat integration. Clean Products Processes. 1999, 1: 91-106. 


\section{Please cite the following article at:}

Sharifzadeh M, Rashtchian D, Pishvaie MR, Thornhill NF, (2011). Energy induced separation network synthesis of an olefin compression section: a case study. Industrial \& Engineering Chemistry Research, 50 (3), 1610-1623, (Link).

(14) El-Halwagi, M. M.; Parthasarathy, G. Optimum mass integration strategies for condensation and allocation of multicomponent VOCs. Chem. Eng. Sci. 2000, 55: 881-895.

(15) El-Halwagi, M. M.; Shelley, M. D. Component-less design of recovery and allocation systems: a functionality-based clustering approach. Comput. Chem. Eng. 2000, 24: 2081-2091.

(16) Hamad, A.; Fayed, M. E. Simulation-aided optimization of volatile organic compounds recovery using condensation. Chemical Engineering Research and Design 2004, 82(A7): 895906.

(17) Zhelev, T. The conceptual design approach-A process integration approach on the move. Resour. Conserv. Recycl. 2007, 50: 143-157.

(18) Othmers, K.; Encyclopedia of Chemical Technology. 4th ed., Wiley: 1998.

(19) Shukri T. LNG technology selection, Hydrocarbon Engineering Feb 2004.[On-line] Available via internet at http://www.fwc.com/publications/tech_papers/files/TariqLNG.pdf, (accessed September, 26, 2010)

(20) Pillarella M. R.; Bronfenbrenner J. C.; Liu Y.; Roberts M. J.; Large LNG Trains: developing the optimal process cycle. [On-line] Available via internet at http://www.airproducts.com/NR/rdonlyres/A02F12BB-3DDC-404D-B5E5-

DA229DB35DC8/0/LargeLNGTrains.pdf , (accessed September, 26, 2010)

(21) Zhang J.; Wen Y.; Xu Q.. Multiobjective Optimization for Design and Operation of the Chilling Train System in Ethylene Plants. Ind. Eng. Chem. Res. 2010, 49 (12), pp 5786-5799. DOI: $10.1021 /$ ie100455g.

(22) Nogal F. D.; Kim J.; Perry S.; Smith R. Optimal Design of Mixed Refrigerant Cycles. Ind. Eng. Chem. Res. 2008, 47, 8724-8740. DOI: 10.1021/ie800515u

(23) Walas, S. M. Chemical Process Equipment: Selection and Design. $2^{\text {nd }}$ ed., Gulf Professional Publishing, 2005.

(24) Ulrich, G.D.; Vasudevan, P.T.; How to Estimate Utility Costs. Chem. Eng. 2006; 113 (4), 66-69.

(25) ICIS Pricing, Chemical process and chemical industry trends. [On-line] Available via internet at http://www.icispricing.com/, (accessed April 12, 2008)

(26) Kabadi, V. N.; Danner, R.P., A Modified Soave-Redlich-Kwong Equation of State for Water-Hydrocarbon Phase Equilibria, Ind. Eng. Chem. process Des. 1985, Dev. 24, 537-541.

(27) Heckl, I.; Kovács, Z.; Friedler, F.; Fan, L. T. Super-structure generation for separation network synthesis involving different separation methods. Chemical Engineering Transaction 2003, 3: 1209-1214. 
Please cite the following article at:

Sharifzadeh M, Rashtchian D, Pishvaie MR, Thornhill NF, (2011). Energy induced separation network synthesis of an olefin compression section: a case study. Industrial \& Engineering Chemistry Research, 50 (3), 1610-1623, (Link).

(28) El-Halwagi M. M.; Pollution prevention through process integration: systematic design tools. 1st ed., Academic Press: San Diego, 1997.

(29) Douglas, J. Conceptual Design of Chemical Processes. McGraw-Hill: 1988.

(30) Customization Guide, Aspen HYSYS, Version Number V7.1, Aspen Technology, Inc,: Burlington, MA, 2009.

\section{List of Figures}

Figure 1. Problem statement of synthesizing energy induced separation network.

Figure 2. Olefin plant block diagram including hot, compression, cold and pyrolysis gasoline hydrogenation sections.

Figure 3. Overall PFD of Compressor Sections.

Figure 4. Superstructure representation of the olefin compression section synthesis problem for $\mathrm{N}=7$ (reference to table 9).

Figure 5. The model of two-stage turbine for optimization of HHPS consumption. $\mathrm{F}^{\mathrm{HHPS}-\mathrm{IN}}$ is generated steam in hot section furnaces and $\mathrm{F}^{\mathrm{HPS}-\mathrm{OUT}}$ is the excess steam to be exported to the site HPS header.

Figure 6. Temperature-pressure diagram for a five-stage compression section

Figure 7. Simulation-Optimization framework for EISENs.

Figure 8. Optimum solution of olefin compressor section synthesis task.

\section{List of Tables}

Table 1. One-to-one correspondence between olefin compression section and general characteristics of EISENs.

Table 2. Optimization variables.

Table 3. Cracked gas inlet stream conditions (second column). Pyrolysis gasoline stream conditions are compared for the synthesized process and in-operation ARPC ${ }^{\circledR}$ plant (third and fourth column).

Table 4. Cooling water and steam level conditions in the compression section

Table 5. Specifications of GA algorithm used in this case study

Table 6. Operating/fixed costs values for the number of compression stages $n^{c}=4,5,6,7$

Table 7. Optimum approach temperature for enumerated $n^{c}=4,5,6,7$

Table 8. Optimum pressure ratios for enumerated $n^{c}=4,5,6,7$ 
Please cite the following article at:

Sharifzadeh M, Rashtchian D, Pishvaie MR, Thornhill NF, (2011). Energy induced separation network synthesis of an olefin compression section: a case study. Industrial \& Engineering Chemistry Research, 50 (3), 1610-1623, (Link).

Table 9. Optimum sink/source configuration for enumerated $n^{c}=4,5,6,7$ (referring to Figure 4 superstructure)

Table 10. Economical comparison between optimal mass integration and extreme patterns of condensate flow.

Table 11. Comparison between existing and synthesized compression section

Table 12. Achievements of the simulation-optimization framework in addressing the challenges of EISEN synthesize problem. 